\title{
Spliceosome Structure and Function
}

\section{Cindy L. Will and Reinhard Lührmann}

Max Planck Institute for Biophysical Chemistry, Department of Cellular Biochemistry, Am Fassberg 11, 37077

Göttingen, Germany

Correspondence: Reinhard.Luehrmann@mpi-bpc.mpg.de

\section{SUMMARY}

Pre-mRNA splicing is catalyzed by the spliceosome, a multimegadalton ribonucleoprotein (RNP) complex comprised of five snRNPs and numerous proteins. Intricate RNA-RNA and RNP networks, which serve to align the reactive groups of the pre-mRNA for catalysis, are formed and repeatedly rearranged during spliceosome assembly and catalysis. Both the conformation and composition of the spliceosome are highly dynamic, affording the splicing machinery its accuracy and flexibility, and these remarkable dynamics are largely conserved between yeast and metazoans. Because of its dynamic and complex nature, obtaining structural information about the spliceosome represents a major challenge. Electron microscopy has revealed the general morphology of several spliceosomal complexes and their snRNP subunits, and also the spatial arrangement of some of their components. X-ray and NMR studies have provided high resolution structure information about spliceosomal proteins alone or complexed with one or more binding partners. The extensive interplay of RNA and proteins in aligning the pre-mRNA's reactive groups, and the presence of both RNA and protein at the core of the splicing machinery, suggest that the spliceosome is an RNP enzyme. However, elucidation of the precise nature of the spliceosome's active site, awaits the generation of a high-resolution structure of its RNP core.

\section{Outline}

1 Introduction

2 Cis-acting pre-mRNA elements and the catalytic steps of splicing

3 Intron- and exon-defined spliceosome assembly pathways

4 A dynamic network of RNA-RNA interactions in the spliceosome and the catalytic role of RNA
5 A conformational two-state model for the spliceosome's catalytic center

6 The spliceosome possesses a complex and dynamic protein composition

7 A rich protein composition affords flexibility to the metazoan spliceosome

8 Splice site recognition involves the coordinated action of RNA and protein

Editors: John F. Atkins, Raymond F. Gesteland, and Thomas R. Cech

Additional Perspectives on RNA Worlds available at www.cshperspectives.org

Copyright (C) 2011 Cold Spring Harbor Laboratory Press; all rights reserved; doi: 10.1101/cshperspect.a003707

Cite as Cold Spring Harb Perspect Biol 2011;3:a003707 
9 Proteins facilitate structural rearrangements in the spliceosome

10 Posttranslational protein modifications also contribute to splicing dynamics

11 Structure of the spliceosomal snRNPs and non-snRNP splicing factors

12 High resolution structures of snRNP and/or spliceosome components

13 Crystal structure of the human U1 snRNP

14 Elucidation of the spatial organization of spliceosomal complexes using biochemical probes
15 Electron microscopy of spliceosomal complexes

16 Localization of regions of the pre-mRNA in the spliceosome via EM

$173 \mathrm{D}$ structures of the spliceosome obtained by EM

18 Summary

References

\section{INTRODUCTION}

Most eukaryotic genes are expressed as precursor mRNAs (pre-mRNAs) that are converted to mRNA by splicing, an essential step of gene expression in which noncoding sequences (introns) are removed and coding sequences (exons) are ligated together. Whereas some exons are constitutively spliced - that is, they are present in every mRNA produced from a given pre-mRNA - many are alternatively spliced to generate variable forms of mRNA from a single pre-mRNA species. Alternative splicing is prevalent in higher eukaryotes and it enhances their complexity by increasing the number of unique proteins expressed from a single gene (Nilsen and Graveley 2010). Unraveling splicing at the molecular level is not only important for understanding gene expression, but it is also of medical relevance, as aberrant pre-mRNA splicing is the basis of many human diseases or contributes to their severity (Novoyatleva et al. 2006; Ward and Cooper 2010).

Nuclear pre-mRNA splicing is catalyzed by the spliceosome, a multi-megadalton ribonucleoprotein (RNP) complex. Both the conformation and composition of the spliceosome are highly dynamic, affording the splicing machinery its accuracy and at the same time flexibility. Two unique spliceosomes coexist in most eukaryotes: the U2-dependent spliceosome, which catalyzes the removal of U2-type introns, and the less abundant U12-dependent spliceosome, which is present in only a subset of eukaryotes and splices the rare U12-type class of introns (reviewed by Patel and Steitz 2003). This article focuses on recent advances in our understanding of the structure and function of the U2-dependent spliceosome, with emphasis on constitutive as opposed to alternative pre-mRNA splicing. For more in-depth reviews of alternative splicing and its regulation the reader is referred to several recent reviews
(Chen and Manley 2009; Matlin et al. 2005; Black 2003; Smith and Valcárcel 2000).

\section{CIS-ACTING PRE-mRNA ELEMENTS AND THE CATALYTIC STEPS OF SPLICING}

Information provided by a pre-mRNA that contributes to defining an intron is limited to short, conserved sequences at the $5^{\prime}$ splice site (ss), $3^{\prime}$ ss and branch site (BS) (Fig. 1)(see also Burge et al. 1999). The BS is typically located 18-40 nucleotides upstream from the 3'ss and in higher eukaryotes is followed by a polypyrimidine tract (PPT) (Fig. 1B). Different splice site and branch site sequences are found in U2- versus U12-type introns (Burge et al. 1999). The U2-type consensus sequences found in the budding yeast Saccharomyces cerevisiae exhibit a higher level of conservation than those in metazoans (Fig. 1B). Additional, cis-acting pre-mRNA elements include exonic and intronic splicing enhancers (ESEs and ISEs) or silencers (ESSs and ISSs). They are typically short and diverse in sequence and modulate both constitutive and alternative splicing by binding regulatory proteins that either stimulate or repress the assembly of spliceosomal complexes at an adjacent splice site (reviewed by Smith and Valcárcel 2000; Wang and Burge 2008).

Nuclear pre-mRNA introns are removed by two consecutive transesterification reactions (reviewed by Moore et al. 1993). First, the $2^{\prime} \mathrm{OH}$ group of the branch adenosine of the intron carries out a nucleophilic attack on the $5^{\prime}$ ss. This results in cleavage at this site and ligation of the $5^{\prime}$ end of the intron to the branch adenosine, forming a lariat structure (Fig. 1A). Second, the $3^{\prime}$ ss is attacked by the $3^{\prime} \mathrm{OH}$ group of the $5^{\prime}$ exon, leading to the ligation of the $5^{\prime}$ and $3^{\prime}$ exons (forming the mRNA), and release of the intron 
(Fig. 1A). The intermediates and products of pre-mRNA splicing are similar to those generated during the removal of group II self-splicing introns (see Jacquier 1990). This similarity led to the hypothesis that catalysis of pre-mRNA splicing is also RNA-based. Likewise similar to group II self-splicing introns, it was recently shown that, under the appropriate conditions, the chemical steps of nuclear premRNA splicing are reversible (Tseng and Cheng 2008), which further emphasizes the mechanistic similarities between the two systems. These studies also underscore the dynamic nature of the spliceosome during the catalytic phase of splicing, as discussed later.

\section{INTRON- AND EXON-DEFINED SPLICEOSOME ASSEMBLY PATHWAYS}

To compensate for the limited information contained in the splicing substrate itself, a large number of trans-acting factors interact with the pre-mRNA to form the spliceosome, in which the reactive groups of the pre-mRNA are spatially positioned for catalysis. The U2-dependent spliceosome is assembled from the U1, U2, U5, and U4/U6 snRNPs and numerous non-snRNP proteins. The main subunits of the U12-dependent spliceosome, in contrast, are the U11, U12, U5, and U4atac/U6atac snRNPs (reviewed by Patel and Steitz 2003). Each snRNP consists of an snRNA (or two in the case of U4/U6), a common set of seven Sm proteins (B/B', D3, D2, D1, E, F, and G) and a variable number of particle-specific proteins (Will and Lührmann 2006) (Fig. 2). The most probable secondary structure of the human spliceosomal U1, U2, U4/U6, and U5 snRNAs are shown in Figure 2; note that several of the snRNAs undergo structural rearrangements during splicing, as described in detail later. In contrast to ribosomal subunits, none of the spliceosomal snRNPs possesses a pre-formed active site and several of them are substantially remodeled in the course of splicing.

Spliceosome assembly occurs by the ordered interaction of the spliceosomal snRNPs and numerous other splicing factors (reviewed by Brow 2002; Matlin and Moore 2007; Staley and Woolford 2009). In the event that an intron does not exceed $\sim 200-250 \mathrm{nts}$, the spliceosome initially assembles across the intron (Fox-Walsh et al. 2005) (Fig. 1C). In the earliest cross-intron spliceosomal complex (i.e., the E complex), the U1 snRNP is recruited to the $5^{\prime}$ ss and non-snRNP factors such as SF1/mBBP and U2AF interact with the BS and PPT, respectively. In a subsequent step, the U2 snRNP stably associates with the BS, forming the A complex (also denoted prespliceosome). The U4/ U6.U5 tri-snRNP, which is pre-assembled from the U5 and U4/U6 snRNPs, is then recruited, generating the precatalytic B complex. Major rearrangements in RNA-RNA and RNA-protein interactions, leading to the destabilization of the U1 and U4 snRNPs, give rise to the activated spliceosome (i.e., the $\mathrm{B}^{\text {act }}$ complex). Subsequent catalytic activation by the DEAH-box RNA helicase Prp2, generates the $\mathrm{B}^{*}$ complex, which catalyzes the first of the two steps of splicing. This yields the $\mathrm{C}$ complex, which in turn catalyzes the second step. The spliceosome then dissociates and, after additional remodeling, the released snRNPs take part in additional rounds of splicing.

In addition to this canonical cross-intron assembly pathway, alternative cross-intron assembly pathways leading to a catalytically active spliceosome likely also exist. For example, a complex containing all five snRNPs (the penta-snRNP) but lacking pre-mRNA has been isolated (Stevens et al. 2002). In the presence of pre-mRNA and additional splicing factors, the penta-snRNP can be chased into an active spliceosome without first undergoing disassembly and then subsequent reassembly. Thus, the generation of an active spliceosome does not necessarily require multiple assembly steps before its activation.

Alternative assembly pathways also exist at the earliest stages of spliceosome assembly, at least in metazoans. Most mammalian pre-mRNAs contain multiple introns whose sizes vary from several hundred to several thousand nucleotides (Deutsch and Long 1999), whereas their exons have a rather fixed length of only $\sim 120 \mathrm{nt}$ on average (Ast 2004). When intron length exceeds $\sim 200-250 \mathrm{nt}$ (which is the case for many introns in higher eukaryotes), splicing complexes first form across an exon (Fox-Walsh et al. 2005), a process called exon definition (Berget 1995). Recent analysis of the coevolution of the $5^{\prime}$ ss and 3'ss support the idea that exon definition is prominent in mammals, but less so in most other metazoans (Xiao et al. 2007). During exon definition, the U1 snRNP binds to the 5'ss downstream of an exon and promotes the association of U2AF with the polypyrimidine tract $/ 3^{\prime}$ ss upstream of it (Fig. 1D). This in turn leads to the recruitment of the U2 snRNP to the BS upstream of the exon. Splicing enhancer sequences within the exon (ESEs) recruit proteins of the SR protein family, which establish a network of proteinprotein interactions across the exon that stabilize the exondefined complex (Hoffman and Grabowski 1992; Reed 2000).

As the chemical steps of splicing occur across an intron, subsequent to exon definition the $3^{\prime}$ ss must be paired across the adjacent intron with an upstream $5^{\prime}$ ss. This switch from an exon-defined to intron-defined splicing complex is currently poorly understood. It is thought that cross-exon interactions are first disrupted and the cross-exon complex is then converted into a cross-intron A complex, where a molecular bridge now forms between $\mathrm{U} 2$ and $\mathrm{U} 1$ bound to an upstream 5'ss (Reed 2000; Smith and Valcárcel 2000). This 
C.L. Will and R. Lührmann

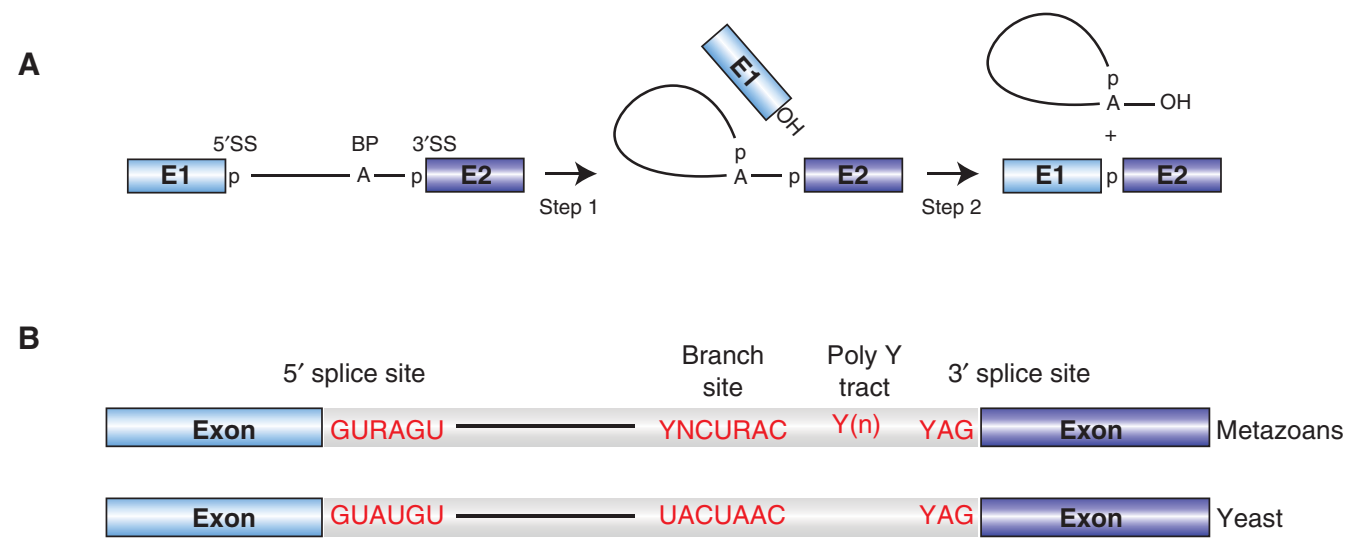

C

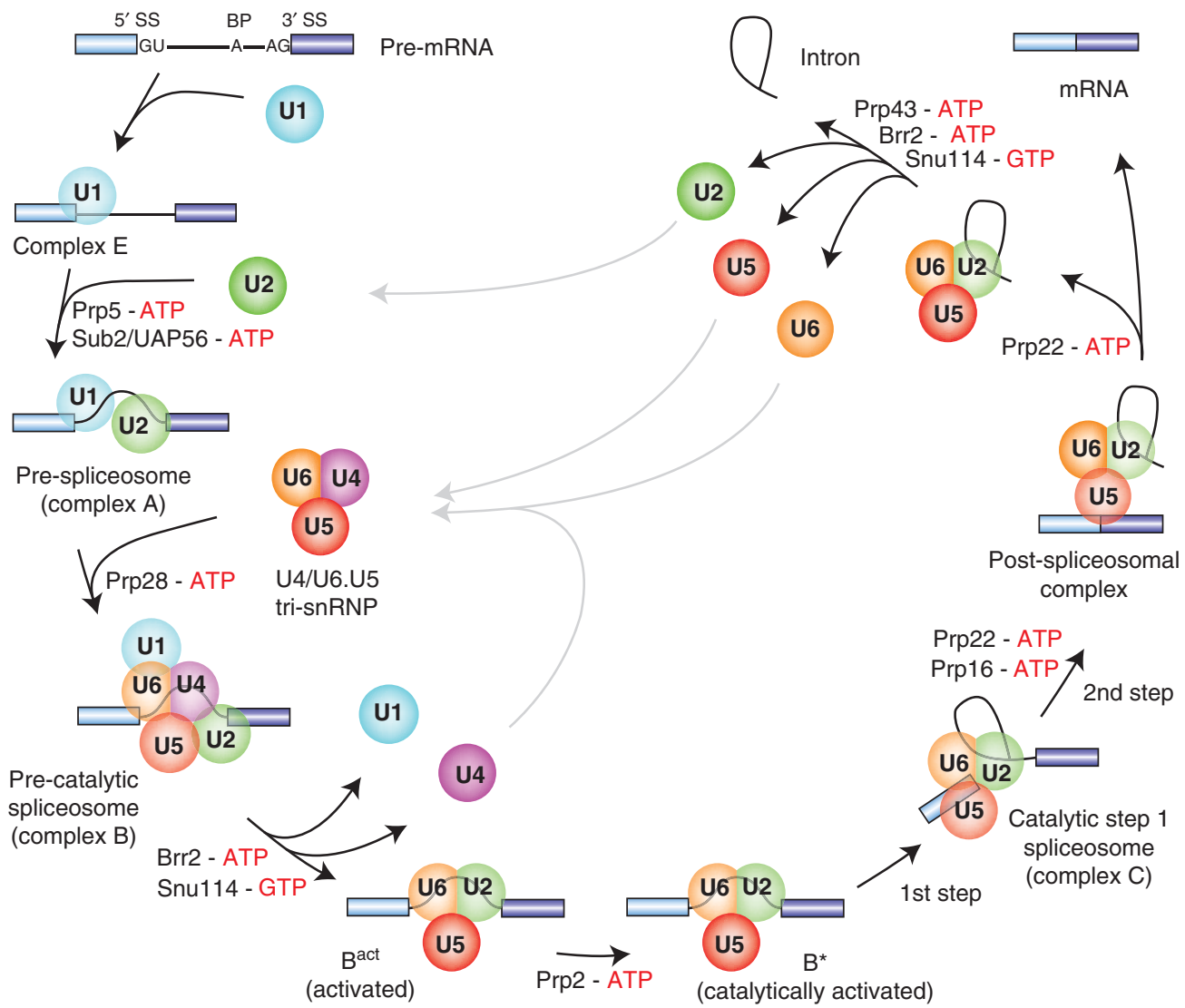

D

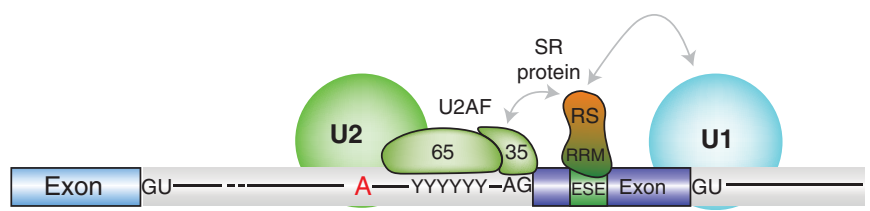

Figure 1. Pre-mRNA splicing by the U2-type spliceosome. (A) Schematic representation of the two-step mechanism of pre-mRNA splicing. Boxes and solid lines represent the exons (E1,E2) and the intron, respectively. The branch site adenosine is indicated by the letter A and the phosphate groups ( $\mathrm{p}$ ) at the $5^{\prime}$ and $3^{\prime}$ splice sites, which are conserved in the splicing products, are also shown. (See facing page for legend.) 

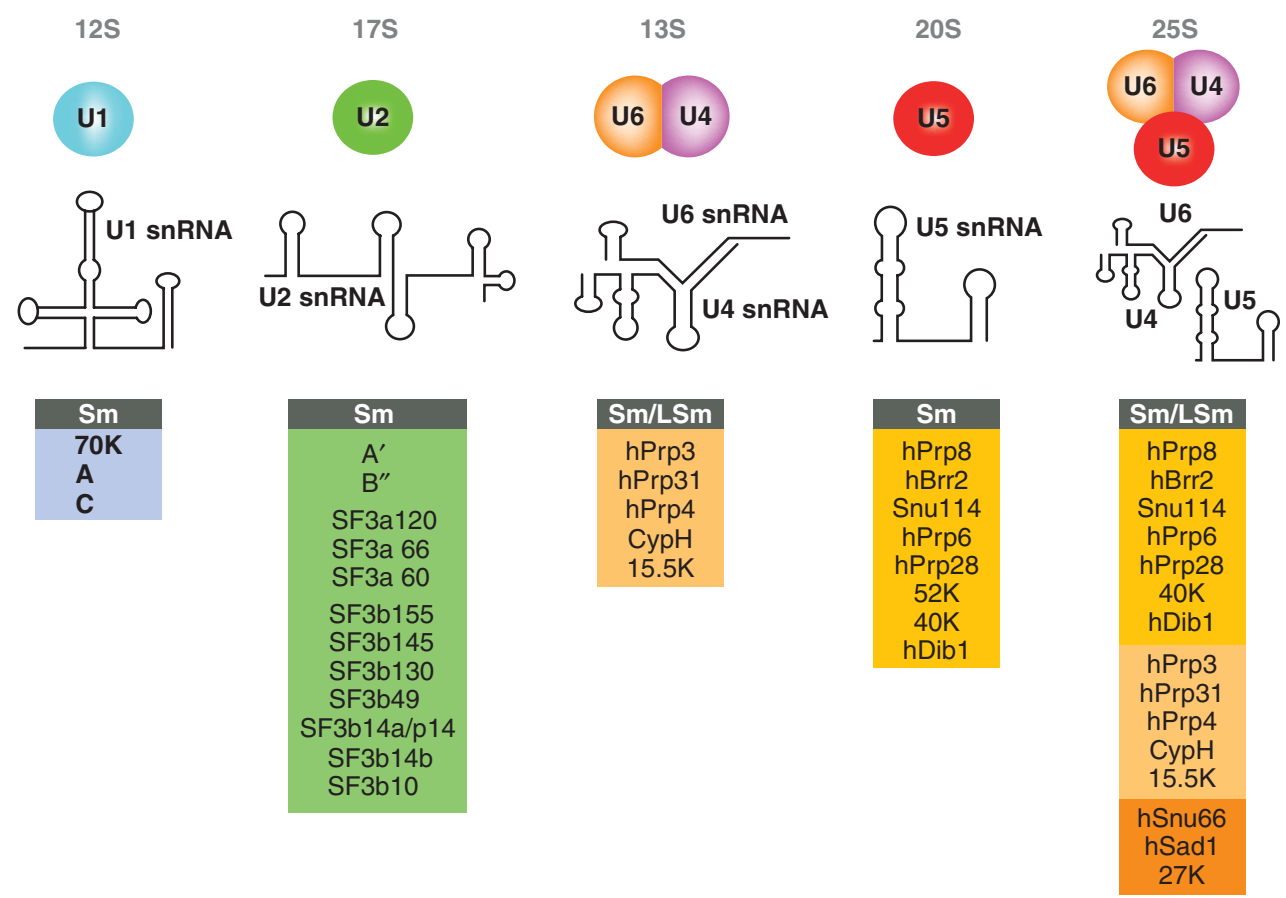

Figure 2. Protein composition and snRNA secondary structures of the major human spliceosomal snRNPs. All seven Sm proteins (B/B', D3, D2, D1, E, F, and G) or LSm proteins (Lsm2-8) are indicated by "Sm" or "LSm" at the top of the boxes showing the proteins associated with each snRNP. The U4/U6.U5 tri-snRNP contains two sets of Sm proteins and one set of LSm proteins.

step is decisive in determining which $5^{\prime}$ and $3^{\prime}$ exon will ultimately be spliced together; recent data indicate that regulation of exon inclusion or skipping during several alternative splicing events occurs during the switch from a cross-exon to cross-intron complex (House and Lynch 2006; Bonnal et al. 2008; Sharma et al. 2008). Recently, exon-defined complexes were shown to contain not only $\mathrm{U} 1$ and U2, but also the U4/U5.U6 tri-snRNP and evidence was provided that it is possible for an exon-defined complex to be converted directly into a cross-intron B complex (Schneider et al. 2010b). These data suggest that multiple pathways leading from an exon-defined complex to an intron-defined spliceosome likely exist and that, although splice site pairing generally occurs during A complex formation (Lim and Hertel 2004), in some instances it can potentially occur at an even later stage of spliceosome assembly.

\section{A DYNAMIC NETWORK OF RNA-RNA INTERACTIONS IN THE SPLICEOSOME AND THE CATALYTIC ROLE OF RNA}

During spliceosome assembly, an intricate RNA-RNA interaction network is formed that is extensively rearranged during catalytic activation of the spliceosome and the catalytic steps of splicing (reviewed by Nilsen 1998). Whereas RNA-RNA secondary interactions in the spliceosome are, for the most part, well-characterized, information about the nature and dynamics of RNA tertiary interactions is scarce. Thus, conformational rearrangements in the RNA

Figure 1. (Continued) (B) Conserved sequences found at the $5^{\prime}$ and $3^{\prime}$ splice sites and branch site of U2-type premRNA introns in metazoans and budding yeast (S. cerevisiae). $\mathrm{Y}=$ pyrimidine and $\mathrm{R}=$ purine. The polypyrimidine tract is indicated by $(\mathrm{Yn})$. (C) Canonical cross-intron assembly and disassembly pathway of the U2-dependent spliceosome. For simplicity, the ordered interactions of the snRNPs (indicated by circles), but not those of non-snRNP proteins, are shown. The various spliceosomal complexes are named according to the metazoan nomenclature. Exon and intron sequences are indicated by boxes and lines, respectively. The stages at which the evolutionarily conserved DExH/D-box RNA ATPases/helicases Prp5, Sub2/UAP56, Prp28, Brr2, Prp2, Prp16, Prp22 and Prp43, or the GTPase Snu114, act to facilitate conformational changes are indicated. $(D)$ Model of interactions occurring during exon definition. 
network of the spliceosome are likely even more complex than current models would suggest.

At the earliest stages of spliceosome assembly, U1 snRNA base pairs with the $5^{\prime}$ ss. U2 snRNA then base pairs with the BS, forming a short U2-BS duplex in which the branch adenosine is bulged out, specifying its $2^{\prime} \mathrm{OH}$ as the nucleophile for the first catalytic step of splicing. Within the U4/U6.U5 tri-snRNP, the U6 and U4 snRNAs are extensively base paired with each other. After association of the tri-snRNP with the A complex, the U4/U6 interaction is disrupted, and the $5^{\prime}$ end of U6 snRNA base pairs with the $5^{\prime}$ ss, displacing the U1 snRNA in the process (Fig. 3 ). In addition, an extensive base pairing network is formed between U6 and U2, which juxtaposes the 5'ss and BS for the first step of splicing. Furthermore, a central region of the U6 snRNA forms an intramolecular stem-loop structure (U6-ISL) that appears to play a crucial role in splicing catalysis (Fig. 3). Tri-snRNP integration also leads to U5 snRNA interactions with exon nucleotides near the 5'ss.

The precise nature of the U6 and U2 snRNA interaction network is the subject of some debate, with two different models currently proposed. In the first, U2 and U6 form three helices (Ia, Ib, and II) (Fig. 3), with the conserved U6 triad AGC forming three base pairs with U2 (corresponding to helix Ib) (Madhani and Guthrie 1992). In an alternative model the AGC triad no longer base pairs with U2 but rather with other U6 nucleotides, extending the U6-ISL and allowing for an intramolecular U2 stemloop, thereby generating a U2-U6 four-way junction (Sun and Manley 1995; Sashital et al. 2004). Recent data have revealed a role for helix I in both steps of splicing, and suggest helix I is disrupted after step 1, but reforms before step 2 (Mefford and Staley 2009). Single molecule analyses of U2 and U6 RNA duplexes suggest that multiple conformations of these RNAs exist (Guo et al. 2009). Thus, U2-U6 interactions appear to be highly dynamic, and these snRNAs likely adopt different conformations at different stages of splicing.

Like U6, the U2 snRNA also appears to undergo intramoleular rearrangements during splicing. Two mutually exclusive stem structures (stem IIa and stem IIc) form within the yeast U2 snRNA in the spliceosome, with recent evidence indicating that $\mathrm{U} 2$ toggles iteratively between these two conformations (Hilliker et al. 2007; Perriman and Ares 2007). Formation of stem IIa promotes the U2/BS interaction during prespliceosome formation. Subsequent formation of stem IIc promotes the first catalytic step of splicing, and a switch back to the stem IIa conformation is required for the second step (i.e., exon ligation). These iterative conformational changes once again underscore the highly dynamic nature of the RNA network within the spliceosome.
A
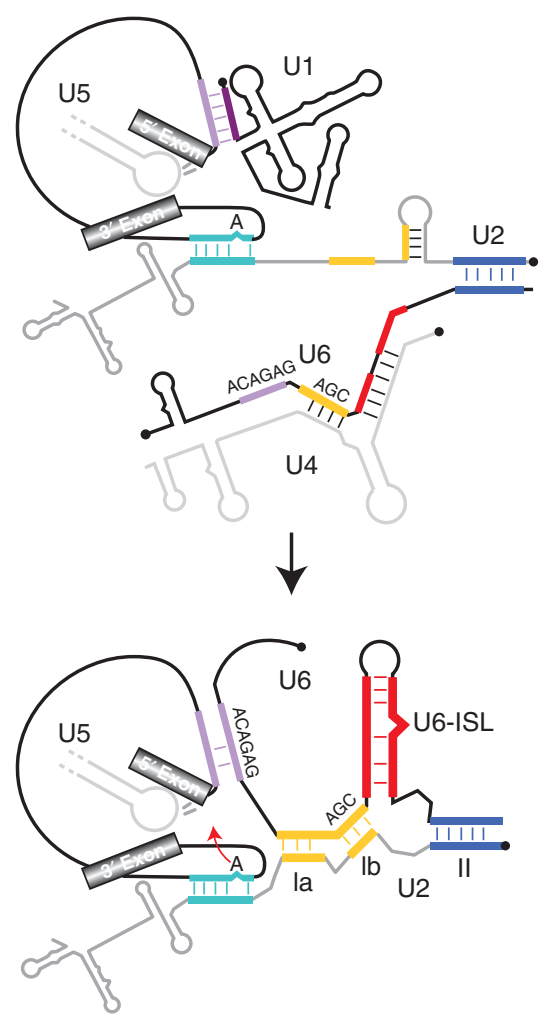

B

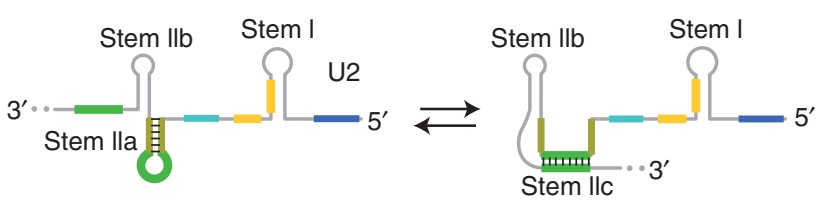

Figure 3. Dynamic network of RNA-RNA interactions in the spliceosome. (A) Exon sequences are indicated by grey boxes and intron sequences by a thin black line. snRNAs are shown schematically (secondary structure as observed in mammals) in grey or black, with those regions engaging in base pairing interactions (indicated by short lines) highlighted in color (not drawn to scale). The $5^{\prime}$ end of the snRNAs is indicated by a black dot. Solely loop 1 of the U5 snRNA is shown. During the transition from a precatalytic spliceosome (upper diagram) to a catalytically activated spliceosome (lower diagram) U1 and U4 are displaced, and U6 and U2 engage in novel base pairing interactions. (B) Conformational toggling of the yeast U2 snRNA. Two mutually exclusive stem structures (stem IIa and stem IIc) are thought to form within the U2 snRNA at different stages of splicing. Solely the $5^{\prime}$ end of the U2 snRNA is shown schematically.

Rearrangements are required after step 1 of splicing to reposition the splicing intermediates for the second step of splicing and allow nucleophilic attack of the $5^{\prime}$ exon at the $3^{\prime}$ ss (reviewed by Smith et al. 2008). The precise timing of these changes and the conformation of the RNARNA interaction network at this stage is not clear. Recent data have shown that the $\mathrm{U} 6 / 5^{\prime}$ ss interaction must be 
disrupted before step 2 (Konarska et al. 2006), The U2/BS interaction is not strictly required for the second step and thus it has been proposed that this interaction is also disrupted between the first and second step of splicing (Smith et al. 2007). The conformation of the U2/U6 interaction is also not entirely clear, but likely helix Ia, Ib, and II are formed at this stage (see previous discussion). Before step 2, U5 also contacts exon nucleotides just downstream of the $3^{\prime}$ ss, and not only tethers the $5^{\prime}$ exon to the spliceosome after step 1, but also aligns both exons for the second catalytic step (reviewed by Turner et al. 2004).

A large body of evidence supports the idea that catalysis of pre-mRNA splicing is at least partially RNA-based with U2 and U6 playing key roles (reviewed by Valadkhan 2005; Wachtel and Manley 2009). Several intermolecular structures formed by the pre-mRNA and the U2, U5, and U6 snRNAs are similar to intramolecular structures formed by self-splicing group II introns (Keating et al. 2010), supporting the idea that pre-mRNA splicing is catalyzed by RNA. Reactions resembling splicing can be catalyzed by short U2 and U6 RNAs in the absence of protein (Valadkhan and Manley 2001; Valadkhan et al. 2007, 2009). However, the kinetics and efficiency of these reactions are slow, suggesting that important cofactors are missing. Furthermore, recent data suggest that RNA generally has a high intrinsic reactivity (Smith and Konarska 2009a), which asks for more profound evidence for the validity of using such snRNA only systems as evidence for RNA-based splicing catalysis (Smith and Konarska 2009b). Perhaps the most compelling evidence that the spliceosome's active site is composed (at least partially) of RNA comes from the crystal structure of a self-splicing group II intron (Toor et al. 2008). These studies revealed that RNA motifs shared by U6 snRNA and group II introns, namely the ACAGAG box and AGC triad, form the basis of the group II intron active site (see also discussion by Keating et al. 2010). On the other hand, data supporting the idea that protein comprises part of the spliceosome's active site also continues to mount (reviewed by Abelson et al. 2008; Wachtel and Manley 2009). Foremost is the recent discovery that the spliceosomal Prp8 protein contains an RNAse H-like domain (see later), suggesting it participates directly in catalysis.

\section{A CONFORMATIONAL TWO-STATE MODEL FOR THE SPLICEOSOME'S CATALYTIC CENTER}

The spliceosome appears to use a single active site for both catalytic steps, and thus the lariat intermediate formed in the first step is thought to be displaced to allow positioning of the $3^{\prime}$ ss for the second step (repositioning of the $5^{\prime}$ exon, in contrast, would theoretically not be required). Thus, the spliceosome would need to exist in two distinct conformational states during the catalytic phase of splicing, binding the substrates differently for the two steps. Based on elegant genetic studies in yeast, demonstrating the existence of two opposing classes of suppressor alleles, an equilibrium between two distinct spliceosome conformations, one that promotes the first step and another conformation that promotes the second step was proposed (Query and Konarska 2004; Konarska and Query 2005). By analogy to the ribosome, where tRNA decoding involves transitions between open and closed conformations at the A site of the 30S subunit, the catalytic center of the spliceosome may thus likewise toggle between open and closed states. Indeed, a number of interactions within the spliceosome appear to toggle (i.e., they are disrupted and then reform at a later stage), such as observed with stem II of the U2 snRNA (see earlier; Hilliker et al. 2007; Perriman and Ares 2007). The demonstration that the catalytic steps of splicing are reversible also support this model (Tseng and Cheng 2008). More recent data suggest that the transition between these two states has multiple phases, including a repositioning step (Liu et al. 2007). Thus, the transition from step 1 to step 2 of splicing likely involves several remodeling events (Smith et al. 2008).

\section{THE SPLICEOSOME POSSESSES A COMPLEX AND DYNAMIC PROTEIN COMPOSITION}

Unlike group II introns, nuclear pre-mRNA introns and the spliceosomal snRNAs do not self-assemble into a catalytically active structure in the absence of spliceosomal proteins. Proteins play critical roles in the recognition and pairing of splice sites, facilitate the dynamics of the RNA-RNA, RNA-protein, and protein-protein interaction networks of the spliceosome, and ensure that the reactive sites of the pre-mRNA are properly positioned for catalysis as discussed in detail later. Proteomic analyses of purified human spliceosomal complexes indicate that over 170 proteins associate with the metazoan spliceosome at some point during the splicing process, with individual assembly intermediates (e.g., B and C complexes) containing significantly fewer $(\sim 110)$ proteins (reviewed by Jurica and Moore 2003; Wahl et al. 2009). Thus, the spliceosome is a particularly protein-rich RNP, with proteins comprising more than two-thirds of its mass in humans in the case of short pre-mRNA introns. Protein-protein, as well as protein-RNA interactions should therefore be prevalent and play functionally important roles in the spliceosome. As a consequence of its complexity, assembly of the spliceosome represents a kinetic challenge that is met, in part, by prepackaging many spliceosomal proteins in the 
form of snRNPs or in stable pre-formed heteromeric complexes. Indeed, $\sim 45$ proteins are recruited to the human spliceosome as part of the spliceosomal snRNPs, whereas non-snRNP proteins comprise the remainder. The composition of the spliceosome is highly dynamic with a remarkable exchange of proteins from one stage of splicing to the next. These changes are also accompanied by extensive remodeling of the snRNPs within the spliceosome.

In addition to human and Drosophila melanogaster spliceosomes (Herold et al. 2009), the protein composition of affinity-purified, in vitro assembled $S$. cerevisiae spliceosomal complexes has now been determined by mass spectrometry (Fabrizio et al. 2009). Analysis of yeast B, Bact and $\mathrm{C}$ complexes revealed that the number of proteins identified in each complex is much lower than that in the corresponding metazoan complex. For example, yeast precatalytic B complexes contained only $\sim 60$ proteins (compared to $\sim 110$ in humans and flies), including essentially all U1, U2, and tri-snRNP proteins plus proteins of the nineteen complex (NTC) and mRNA retention and splicing (RES) complex (Fig. 4). Likewise, yeast $\mathrm{C}$ complexes contained only $\sim 50$ proteins compared to $\sim 110$ in metazoan C complexes. Altogether $\sim 90$ proteins were identified in yeast spliceosomes, nearly all of which have homologs in higher eukaryotes (Fabrizio et al. 2009). Thus, the yeast splicing machinery likely contains the evolutionarily conserved, core set of spliceosomal proteins required for constitutive splicing. Indeed, most of the remaining $\sim 80$ proteins found in human and D. melanogaster spliceosomes have no counterparts in yeast, with many playing a role in alternative splicing, a process that is essentially absent in yeast (Fabrizio et al. 2009).

A dramatic exchange of proteins occurs during spliceosome assembly and activation (Wahl et al. 2009). The same homologous proteins are subject to dissociation/recruitment events during the transition from the $\mathrm{B}$ to $\mathrm{C}$ complex in both metazoans and yeast (Deckert et al. 2006; Bessonov et al. 2008; Fabrizio et al. 2009; Herold et al. 2009), indicating that these compositional changes are an evolutionarily conserved design principle of the spliceosome. In yeast, the most extensive compositional exchange occurs during the transition from the precatalytic B complex to the activated $\mathrm{B}^{\text {act }}$ complex (Fabrizio et al. 2009). During this transition, $\sim 35$ proteins dissociate, including among others all U1 and U4/U6 associated proteins, whereas 12 others are recruited (Fig. 4). Thus, the U4/U6.U5 tri-snRNP undergoes massive remodeling during activation, with all U4/U6 associated proteins, the U4 snRNA and some U5 proteins released. It is presently not clear whether these proteins are destabilized/released concomitantly or in separate steps. Indeed it is not known how many discrete RNP remodeling events occur during splicing. Numerous structurally distinct spliceosome intermediates likely exist, with each RNP rearrangement potentially subjected to regulation. As the U6 snRNA appears to have lost most of its preactivation binding partners, it not only engages in novel base pairing interactions with $\mathrm{U} 2$ but also new protein-RNA interactions are thought to be established (Wahl et al. 2009). Proteins of the NTC complex (or Prp19/CDC5 complex in humans) and related proteins, as well as SR proteins in humans (Shen and Green 2007), likely are involved in tethering the U6 snRNA at this stage (Chan et al. 2003). In humans there is evidence that the U5 snRNP is also remodeled during activation; $\sim 15$ proteins_-including those comprising the human Prp19/CDC5 complex associate stably with U5 at this stage, yielding a remodeled 35S form of the U5 snRNP (Makarov et al. 2002).

The transition from $\mathrm{B}^{\text {act }}$ to $\mathrm{C}$ complex is also accompanied by compositional changes, but to a much lesser extent. In yeast, only two proteins are lost and nine proteins, including step two factors and the trimeric NTR spliceosome disassembly complex, are recruited at this stage (Fig. 4). Because of the low number of proteins recruited at this stage, it has been possible to investigate the role of some of these factors in the catalytic steps of splicing using affinitypurified yeast $\mathrm{B}^{\text {act }}$ complexes of defined composition and adding back recombinant splicing factors (Warkocki et al. 2009; see also below). The ability to restore both steps of S. cerevisiae splicing from purified components should allow a fine dissection of the role of RNA helicases in RNP remodeling events accompanying the catalytic steps of splicing. Interestingly, the U2 snRNP also appears to be substantially remodeled just before, or during, C complex formation both in yeast and humans, with an apparent destabilization/loss of the U2-associated SF3a and SF3b proteins (Bessonov et al. 2008; Fabrizio et al. 2009). This suggests that, although required for the U2/BS interaction during the early stages of splicing, $\mathrm{SF} 3 \mathrm{a} / \mathrm{b}$ are not required after step 1 . This is also consistent with the proposed disruption of the U2/BS interaction after step 1 (Smith et al. 2007).

Recently it was possible to purify human spliceosomal $\mathrm{C}$ complexes that were capable of catalyzing exon ligation on their own (Bessonov et al. 2008). High salt treatment of these C complexes yielded an RNP core consisting of only $\sim 35$ proteins, in which the catalytic RNA-RNA network appeared to be intact. Main components of this spliceosomal RNP core are Prp19/CDC5 proteins and Prp19-related factors, plus U5 proteins including Prp8. These data provide a first glimpse into the RNP core of the step 1 spliceosome and indicate that the aforementioned proteins play a central role in sustaining its catalytically active structure. 


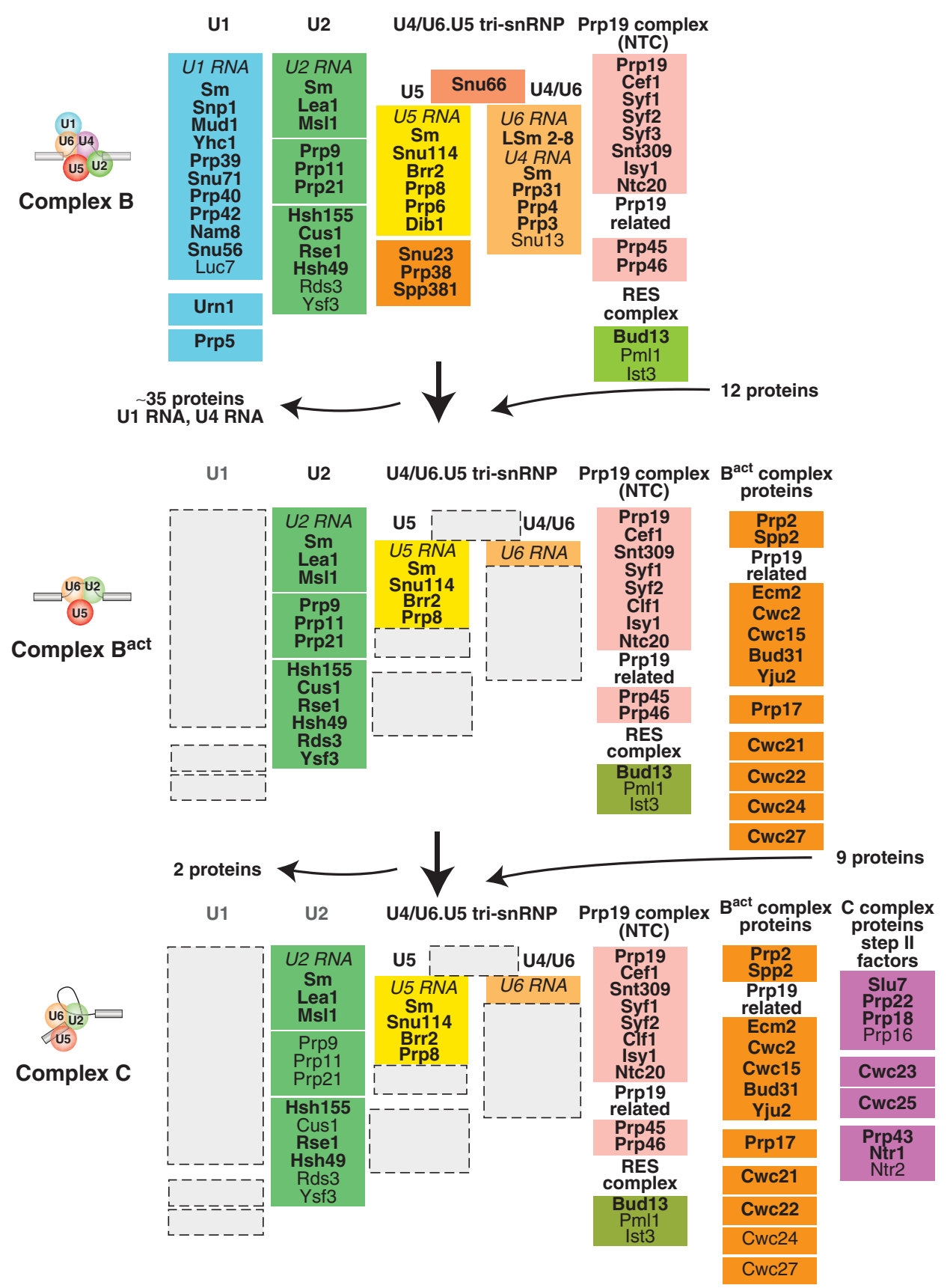

Figure 4. Compositional dynamics of the yeast spliceosome. Proteins identified by mass spectrometry in S. cerevisiae $\mathrm{B}, \mathrm{B}^{\text {act }}$, and $\mathrm{C}$ spliceosomal complexes are shown. Proteins are grouped according to their function or association with an snRNP, protein complex or spliceosomal complex. The relative abundance of the indicated proteins is indicated by light (substoichiometric) or dark (stoichiometric) lettering. (Reprinetd, with permission, from Fabrizio et al. 2009 [C Elsevier].)

\section{A RICH PROTEIN COMPOSITION AFFORDS FLEXIBILITY TO THE METAZOAN SPLICEOSOME}

The highly complex nature of the metazaon spliceosome in terms of its protein composition is puzzling at first glance. However, as mentioned earlier, a large number of human spliceosome-associated proteins play largely regulatory roles in splicing, whereas others are thought to couple splicing to other molecular machines in the nucleus, including those involved in transcription and polyadenylation (reviewed by Maniatis and Reed 2002). In addition, several proteins that co-purify with human spliceosomes 
are loosely associated and/or have redundant functions (e.g., different SR-proteins) and thus are likely not required to splice every pre-mRNA substrate (Wahl et al. 2009). Indeed, recent observations suggest that pre-mRNA substrates differ even in their requirements for core components of the spliceosome, presumably because of different affinities between components of the spliceosome and the various pre-mRNAs they encounter or the redundant nature of splicing signals (Clark et al. 2002; Park et al. 2004; Pleiss et al. 2007). Thus, the compositional complexity of the metazoan spliceosome is likely in part a reflection of the wide variety of pre-mRNA substrates that it must engage and the widespread occurrence of regulated splicing events. The expanded repertoire of spliceosome-associated proteins also affords flexibility to the splicing machinery to quickly respond to changes in the cellular environment.

\section{SPLICE SITE RECOGNITION INVOLVES THE COORDINATED ACTION OF RNA AND PROTEIN}

One of the earliest tasks of the spliceosome is to distinguish bona fide splice sites from the numerous nonauthentic sites found in a pre-mRNA. Proteins contribute to splice site recognition both indirectly by stabilizing snRNA-premRNA base pairing interactions or directly by contacting reactive nucleotides of the pre-mRNA. During splicing, splice sites are recognized multiple times by both protein and RNA, ensuring the remarkable precision of the splicing reaction. Many functionally important binary interactions within the spliceosome are weak. However, the combination of multiple weak interactions enhances the overall stability of the RNP complexes formed, while at the same time affording the spliceosome the plasticity needed for regulated splicing events.

The $5^{\prime}$ ss is initially recognized via base pairing of the U1 snRNA. In metazoans, this interaction is stabilized by the U1-70K and U1-C protein (which directly contacts the $5^{\prime} \mathrm{ss}$ ), as well as members of the SR protein family (reviewed by Will and Lührmann 2006). Recent data indicate that SR proteins, via their RS domain, help to stabilize not only the U1/5'ss base pairing interaction, but also subsequent U6 and U5 contacts with the 5'ss (Shen and Green 2004, $2006,2007)$. In addition to engaging in protein-protein interactions, positively-charged RS domains are thought to selectively contact the pre-mRNA's splicing signals (i.e., the $5^{\prime}$ ss and BS) during the formation of transient snRNA-pre-mRNA duplexes and subsequently promote these interactions by neutralizing the positively charged phosphates of the two RNA strands (Valcárcel et al. 1996; Shen and Green 2006). A dissection of SR protein interactions with the 5 'ss revealed that the RS domain contacts the site of the U6/5'ss interaction during step 1 of splicing, and then shifts to the site of the U5/5'ss interaction before step 2 , mirroring the remodeling of the spliceosome between the two steps of splicing (Shen and Green 2007). The U5 protein $220 \mathrm{~K} / \operatorname{Prp} 8$ also contacts the $5^{\prime}$ ss (as well as the $3^{\prime}$ ss, BS and PPT) (reviewed by Grainger and Beggs 2005). Prp8 has thus been implicated in $5^{\prime}$ ss recognition, and also in aiding to position the $5^{\prime}$ ss within the spliceosome for the first step of splicing. After step 1, 220K/ Prp8 is thought, together with the U5 snRNA, to help align the $5^{\prime}$ ss and $3^{\prime}$ ss for the second step.

Multiple interactions also contribute to the recognition of the BS (reviewed by Will and Lührmann 2006; Wahl et al. 2009). In metazoans, the branch adenosine is initially recognized by $\mathrm{SF} 1 / \mathrm{mBBP}$, which binds cooperatively with the heteromeric dimer U2AF. The $65-\mathrm{kDa}$ subunit of U2AF binds the neighboring polypyrimidine tract, whereas its $35 \mathrm{kDa}$ subunit contacts the $3^{\prime} \mathrm{ss}$ and plays a role in $3^{\prime} \mathrm{ss}$ recognition. In a subsequent step, the U2/BS base pairing interaction is formed, $\mathrm{SF} 1 / \mathrm{mBBP}$ is displaced and the branch adenosine is now contacted by a subunit of the U2-associated SF3b complex, namely p14/SF3b14a. The U2/BS duplex is stabilized by U2AF and subunits of the heteromeric splicing factors SF3a and SF3b, which contact the pre-mRNA in the vicinity of the branch site. During the catalytic steps of splicing, there are likely multiple remodeling events at or near the BS, but these are presently not well-characterized.

\section{PROTEINS FACILITATE STRUCTURAL REARRANGEMENTS IN THE SPLICEOSOME}

The sequential rearrangements in the spliceosome's RNARNA and RNA-protein networks are driven in most cases by members of the $\mathrm{DExD} / \mathrm{H}$-box family of RNA unwindases/RNPases which include Prp5, Sub2/UAP56, Prp28, U5-200K/Brr2, Prp2, Prp16, Prp22, and Prp43 (reviewed by Staley and Guthrie 1998). The energy of ATP hydrolysis by these enzymes is coupled to structural/compositional rearrangements at one or more steps of the splicing cycle (Fig. 1C). Although the precise targets of many of these proteins remain largely unknown, in several cases the mechanisms of their action and regulation are beginning to emerge. The activity of these enzymes must be highly coordinated, a task carried out in part by other spliceosomal components and also modulated in some cases by posttranslational modifications. Several $\mathrm{DExD} / \mathrm{H}$-box proteins also play a key role in ensuring the fidelity of the splicing process by facilitating the discard of aberrant/nonproductive splicing intermediates/products (reviewed by Smith et al. 2008).

The DEAD-box proteins Prp5 and Sub2/UAP56 are required for prespliceosome formation. UAP56/Sub2p is 
thought to facilitate $\mathrm{U} 2$ addition to the spliceosome by displacing Mud2p (the yeast homolog of U2AF) and/or BBP from the BS (Kistler and Guthrie 2001). Thus, some spliceosomal $\mathrm{DExD} / \mathrm{H}$-box proteins appear to directly catalyze RNA-protein rearrangements in the spliceosome rather than unwind RNA duplexes, as initially thought. Studies in humans suggest that Sub2/UAP56 also acts at a later stage of spliceosome assembly, contacting the U4 and U6 snRNAs and potentially contributing to their unwinding (Shen et al. 2008). Prp5p is thought to use ATP hydrolysis to remodel the U2 snRNP, thereby facilitating U2 snRNA binding to the BS. More recent data indicate that Prp5 also plays a role in proofreading the stability of the U2/BS duplex (Xu and Query 2007).

The DEAD-box protein Prp28 catalyzes the exchange of U1 with U6 at the 5'ss (Staley and Guthrie 1999) during the transition from complex B to $\mathrm{B}^{\text {act }}$. Prp28 appears to function by actively disrupting an RNA-protein interaction that stabilizes the $\mathrm{U} 1 / 5^{\prime}$ ss base pairing interaction, namely the interaction between U1-C and the 5'ss (Chen et al. 2001). In humans, phosphorylation of Prp28 is required for its association with the tri-snRNP and for the subsequent stable integration of the tri-snRNP during B-complex formation (Mathew et al. 2008). Whether phosphorylation (or dephosphorylation) of Prp28 modulates its function in releasing $\mathrm{U} 1$ from the $5^{\prime} \mathrm{ss}$ is presently not known.

The DExD/H-box protein Brr2 catalyzes a crucial step in spliceosome activation, namely the unwinding of U4/ U6. Most RNA helicases join the spliceosome transiently at the stage at which their activity is required. Brr2, in contrast, is an integral spliceosome component whose activity must be tightly regulated to prevent premature unwinding of U4/U6. Recent evidence indicates that at least two proteins, Prp8 and the GTPase Snu114, regulate Brr2 activity during spliceosome activation. A carboxy-terminal fragment of Prp8 has been shown to interact with Brr2 and stimulate its helicase activity (Maeder et al. 2009). As this region of Prp8 binds ubiquitin (Bellare et al. 2006) and Prp8 is ubiquinated in the tri-snRNP, it has been suggested that this posttranslational modification ultimately plays a key role in regulating Brr2 activity (Bellare et al. 2008; see also later discussion). U4/U6 unwinding during catalytic activation also requires the U5-associated GTPase Snu114 (Bartels et al. 2002; Brenner and Guthrie 2005), which is homologous to the ribosomal elongation factor EF-2 that catalyzes structural rearrangements in the ribosome during translocation. Recent data indicate that Brr2 activity is blocked by Snu114 when it is bound to GDP, but not by its GTP bound form (Small et al. 2006). Snu114 interacts with the same region of Prp8 as Brr2 does, namely its carboxyl terminus, suggesting this region of Prp8 may additionally coordinate Snu114 control of Brr2. Other proteins playing a role in the rearrangements accompanying catalytic activation include members of the yeast NTC or human Prp19/CDC5 complex. During spliceosome activation, the NTC complex acts subsequent to U4 dissociation, apparently by stabilizing the association of U5 and U6 with the activated spliceosome (Chan et al. 2003). More recent data indicate that the NTC plays a key role in specifying the proper interaction of U5 and U6 with the pre-mRNA substrate before step 1 (Chan and Cheng 2005).

The DExH/D-box protein Prp2 is required before step 1 of splicing and it promotes a poorly understood remodeling event that converts $\mathrm{B}^{\text {act }}$ into the catalytically active $\mathrm{B}^{*}$ complex. Studies with purified yeast spliceosomes containing a heat-inactivated Prp2 mutant (prp2-1) revealed a major conformational rearrangement, as evidenced by gradient sedimentation analysis and electron microscopy, upon complementation with purified Prp2 in the presence of ATP (Warkocki et al. 2009). This conformational change leads to a destabilization of SF3a and SF3b proteins, that likely exposes the BS before step 1 (Warkocki et al. 2009). In yeast, Spp2, which recruits Prp2 to the spliceosome (Silverman et al. 2004), Yju2 (Lui et al. 2007), the NTC component Isyl (Villa and Guthrie 2005) and Cwc25 (Chui et al. 2009; Warkocki et al. 2009) also have been shown to promote step 1 of splicing.

The DExD/H-box ATPase Prp16 promotes a conformational rearrangement in the spliceosome required for step 2 of splicing, the precise nature of which is unclear. In yeast, Prp16 interacts genetically with Prp8 (Query and Konarska 2004), Isy1 (Villa and Guthrie 2005) and U6 snRNA at this stage (Madhani and Guthrie 1994), suggesting it acts on a structure containing one or more of these components. Prp16 also regulates the fidelity of branch site recognition, promoting the discard of aberrant lariat intermediates (Burgess and Guthrie 1993a). These early studies led to a kinetic proof reading model (based on a model initially proposed for proofreading during translation) in which the rate of ATP hydrolysis by Prp16 (or in general by any other ATPase) is proposed to act as a timer to regulate the outcome of two competing events, in this case either discard of an aberrant intermediate or its participation in the next step of splicing (Burgess and Guthrie 1993b). Prp18, Slu7, and Prp22, which act after Prp16, also promote the second step, apparently also by aiding the alignment of the reactive groups responsible for step 2 (reviewed by Umen and Guthrie 1995; Smith et al. 2008). For example, recent data suggest that the interaction of U 5 loop 1 with both exons is stabilized by Prp18 at this stage (Crotti et al. 2007).

The DExD/H-box protein Prp22 not only functions subsequent to Prp16 during step 2, but it is also required 
for the release of the mRNA product from the spliceosome. Prp22 is deposited on the mRNA downstream of the exonexon junction, concomittant with an RNP rearrangement occurring during step 2 of splicing (Schwer 2008). It is then thought to displace U5 from the mRNA by disrupting Prp8 and U5 snRNA interactions with exon nucleotides, leading to mRNA release (Aronova et al. 2007; Schwer 2008). Prp 22 also plays a role in ensuring the fidelity of exon ligation by repressing the splicing of aberrant splicing intermediates (Mayas et al. 2006).

Spliceosome components must function in multiple rounds of splicing, and thus sequestration of splicing factors in postcatalytic or defective splicing complexes would be detrimental. Release of the excised intron from the postsplicing complex, which is accompanied by release of $\mathrm{U} 2$, U5, and U6, is catalyzed by Prp43. In yeast, Ntr1 and Ntr2 (which form a stable complex) are also required for spliceosome disassembly (Tsai et al. 2005) and recruit Prp43 to the spliceosome (Tsai et al. 2007). Ntr1 acts as an accessory factor that on binding to Prp43, stimulates its helicase activity (Tanaka et al. 2007). Both proteins have also been implicated in a turnover pathway for defective spliceosomes (Pandit et al. 2006). Brr2 and Snu114 also are required at this stage, where they are thought to facilitate unwinding of U2/U6 duplexes in the postsplicing complex (Small et al. 2006).

\section{POSTTRANSLATIONAL PROTEIN MODIFICATIONS ALSO CONTRIBUTE TO SPLICING DYNAMICS}

Posttranslational modifications also promote critical RNP rearrangements essential for splicing. The role of reversible protein phosphorylation in splicing continues to grow, and evidence has now been provided that other forms of posttranslational modification also affect the splicing process. The essential role of SR protein phosphorylation/dephosphorylation in splicing is well documented (reviewed by Misteli 1999; Soret and Tazi 2003), with de/phosphorylation shown to modulate protein-protein and proteinRNA interactions involving RS domains (Xiao and Manley 1997; Shin et al. 2004). Indeed, protein modifications likely play a critical role in splicing dynamics by influencing the stability of protein-protein interactions. Dephosphorylation of several spliceosomal phosphoproteins is required for the catalytic steps of splicing, with PP1/PP2A phosphatases playing key roles at this stage. For example, dephosphorylation of the U1-70K protein (Tazi et al. 1993) and SR protein ASF/SF2 (Cao et al. 1997) is required for step 1 in mammals. The U2-associated SF3b155 protein is hyperphosphorylated just before, or during, step 1 of splicing (Wang et al. 1998). SF3b155 and U5-116K (human
Snu114) are dephosphorylated by PP1/PP2A phosphatases concomitant with step 2 of splicing (Shi et al. 2006). It was thus proposed that dephosphorylation of these proteins facilitates essential structural rearrangements in the spliceosome during the transition from the first to the second step of splicing (Shi et al. 2006).

Several human tri-snRNP proteins were recently shown to be phosphorylated and their phosphorylation was linked to the stable integration of the U4/U6.U5 tri-snRNP during B-complex formation. Specifically, the human trisnRNP protein hPrp28 is phosphorylated by the kinase SRPK2 and in the absence of Prp28 phosphorylation, B-complex formation is blocked (Mathew et al. 2008). In addition, human Prp6 and Prp31, both tri-snRNP proteins, are phosphorylated during B-complex formation by Prp4 kinase (Schneider et al. 2010a). The latter kinase is required for stable association of the tri-snRNP during B-complex formation, suggesting that phosphorylation of Prp6 and Prp31 may contribute to this step. Thus, in higher eukaryotes, numerous phosphorylation events contribute to spliceosome assembly, which could therefore potentially be modulated at multiple regulatory checkpoints. Both Prp4 kinase and SRPK2 are absent from S. cerevisiae. The latter kinase phosphorylates RS domains that, in higher eukayotes, are typically found in SR proteins and also other spliceosomal proteins (including hPrp28), but are for the most part absent in S. cerevisiae. Indeed, there appear to be generally fewer phosphorylation events during splicing in S. cervisiae and thus fewer regulatory targets/switches. This is consistent with the paucity of alternative splicing events in yeast, and also with the more flexible nature of interactions among spliceosomal components in higher eukaryotes which thus may be more susceptible to fine tuning by posttranslational modifications.

Aside from phosphorylation, a number of other posttranslational modifications have been implicated in premRNA splicing. Proteomic analyses have revealed that numerous spliceosomal proteins are acetylated (Choudhary et al. 2009), and small-molecule inhibitors of acetylation block spliceosome assembly in vitro at distinct stages before activation (Kuhn et al. 2009), suggesting that acetylation plays a role in splicing. U2AF65 was shown to undergo lysyl-hydroxylation and the responsible enzyme, Jmjd6, was shown to play a role in splicing regulation (Webby et al. 2009). Finally, evidence was provided that ubiquitination plays an important role in splicing (Bellare et al. 2008). Specifically, it was shown to be required to maintain tri-snRNP levels by apparently inhibiting the premature unwinding of U4/U6 (Bellare et al. 2007). These studies also revealed that Prp8 is ubiquitinated within the tri-snRNP. Given Prp8's known role in modulating Brr2 activity (see earlier discussion), it was postulated 
that ubiquitination/deubiquitination of Prp8 likely plays an indirect role in regulating both U4/U6 unwinding during catalytic activation, and U2/U6 unwinding during spliceosome disassembly (Bellare et al. 2008).

\section{STRUCTURE OF THE SPLICEOSOMAL SnRNPs AND NON-snRNP SPLICING FACTORS}

Insight into the spliceosome's structural organization initially came from the characterization of its main subunits, namely the snRNPs. Much has been learned about protein-protein and protein-RNA interactions within the spliceosomal snRNPs (reviewed by Kambach et al. 1999a; Will and Lührmann 2006) and a complete picture of the spatial arrangement of snRNP components is slowly emerging via ultrastructural analyses of the snRNPs and their components.

Single-particle electron cryomicroscopy has been instrumental in elucidating the morphology and architecture of the spliceosomal snRNPs. Low to moderate resolution ( 10-30 $\AA$ ) 3D structures of the U1 snRNP, the heteromeric protein complex SF3b (a major subunit of the U2 snRNP), the U11/U12 di-snRNP, and the U4/U6.U5 tri-snRNP and its subunits U5 and U4/U6, have been obtained by EM (reviewed by Stark and Lührmann 2006). The resolution of the $\mathrm{U} 1$ snRNP $(\sim 10 \AA), \mathrm{SF} 3 \mathrm{~b}(\sim 10 \AA)$, and the U11/U12 di-snRNP $(\sim 12 \AA)$ was sufficient to allow the localization of a subset of their protein components by fitting known structures or subdomains of these proteins into the 3D EM map. For example, the RRMs of SF3b49 and SF3b14a/p14 and the carboxy-terminal HEAT repeats of SF3b155, could be localized in the 3D reconstructions of the isolated SF3b complex and also in the U11/U12 di-snRNP (which contains SF3b) (Golas et al. 2003, 2005). The large body of biochemical and structural data available for the U1 snRNP, coupled with its relatively simple composition, allowed the generation of a 3D model of the human U1 snRNP, in which all of its components could be localized (Stark et al. 2001).

EM studies have recently shed light on the molecular architecture of the U4/U6.U5 tri-snRNP. 3D structures of the individual subunits of the human tri-snRNP, namely the U5 and U4/U6 snRNPs, together with the 3D structure of the U4/U6.U5 tri-snRNP have now been obtained by performing cryo-negative stain electron microscopy (Fig. 5A)(Sander et al. 2006). The tri-snRNP possesses an elongated, tetrahedral shape with dimensions of 305 $\AA \times 200 \AA \times 175 \AA$ and its 3D structure could be determined at a resolution of $\sim 25 \AA$. The position of the U5 and U4/ U6 snRNPs within the tri-snRNP could be localized by fitting their 3D structures into the 3D map of the tri-snRNP
(Fig. 5A). The positions of the $3 \mathrm{G}$ cap and loop 1 of the U5 snRNA were mapped by immunolabeling followed by EM. Because of the low resolution of the EM map, it was not possible to localize individual tri-snRNP proteins using information about their structure obtained by NMR or X-ray crystallography.

By analysing purified yeast U4/U6.U5 tri-snRNPs containing proteins with a genetically introduced tag, the structural arrangement of U5- and U4/U6-specific proteins in the $S$. cerevisiae tri-snRNP was determined by EM (Häcker et al. 2008). 2D EM images of the "wildtype" yeast tri-snRNP_which has a morphology very similar to the human tri-snRNP-or those containing a tagged trisnRNP protein were generated and compared. In this way, the carboxyl terminus of the U5 proteins Prp8, the DExH/D-box helicase Brr2, and GTPase Snu114 could be localized in the main body of the tri-snRNP, demonstrating

A

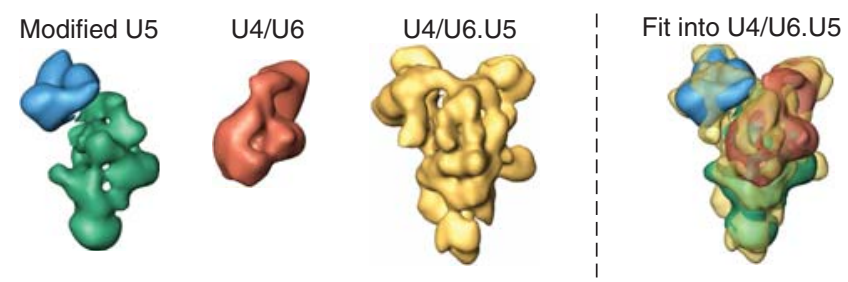

B

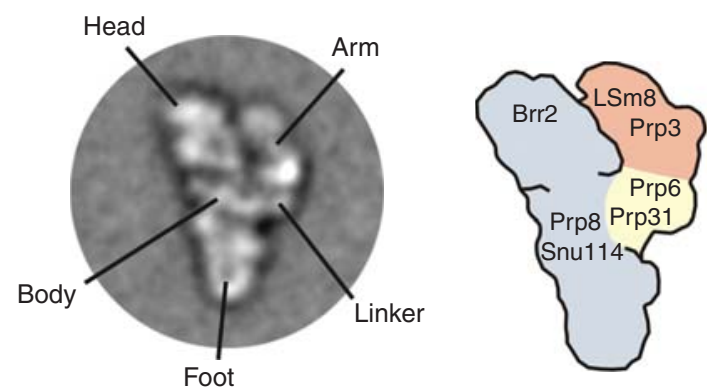

Figure 5. Three dimensional EM structure of the U4/U6.U5 tri-snRNP and localization of functionally important tri-snRNP proteins. (A) 3D reconstructions of the human U5 and U4/U6 snRNPs and tri-snRNP, and fitting of U5 and U4/U6 into the tri-snRNP 3D map (adapted, with permission, from Sander et al. 2006 [ (C) Elsevier]). The head domain of U5 (highlighted blue) appears to be flexible and it is positioned in the U5 snRNP 3D reconstruction shown in a manner favorable for fitting into the tri-snRNP 3D map. (B) Left, representative $2 \mathrm{D}$ class average of the affinity purified $S$. cerevisiae U4/U6.U5 tri-snRNP as visualized by negative-stain electron microscopy after mild fixation using the Grafix protocol. The main structural domains are indicated. Right, cartoon model of the yeast tri-snRNP. Area corresponding to the U5 and U4/U6 snRNPs and the linker region are shaded grey, orange, or yellow, respectively. The position of the carboxyl terminus of several tri-snRNP proteins is indicated (adapted from Häcker et al. 2008). 
that the U5 snRNP is located in this region (Fig. 5B). In addition, the U4/U6-proteins LSm8 and Prp3 were mapped to the so-called "arm" - indicating the U4/U6 snRNP is located in this region-and the tri-snRNP-specific bridging proteins Prp6 and Prp31 were detected in the linker region of the tri-snRNP (Fig. 5B). The spatial organization of Brr2 relative to the U4/U6 snRNP has important implications for the mechanism whereby Brr2 facilitates U4/U6 snRNA unwinding during catalytic activation (Häcker et al. 2008). These data thus provide a structural framework for potential mechanisms whereby the molecular motor proteins (Prp8, Brr2, and Snu114) of the tri-snRNP act. A similar genetic tagging approach was used to map the position of the LSm 2-8 proteins in the yeast U6 snRNP, supporting the previously proposed order of the Lsm proteins within the Lsm ring and elucidating their spatial organization relative to the U6-associated Prp24 protein (Karaduman et al. 2008). In the future, the introduction of genetic tags can potentially be used to map via EM the location of these and other proteins in spliceosomal complexes.

\section{HIGH RESOLUTION STRUCTURES OF SnRNP AND/OR SPLICEOSOME COMPONENTS}

Because of its highly dynamic and complex nature, as well as the limited amounts that can be purified, obtaining structural information about the spliceosome at the atomic level represents a major challenge. X-ray crystallography and NMR analyses have been limited (with one notable exception; see later) to individual snRNP and spliceosomal proteins alone or in complex with RNA or a protein binding partner. Crystal structures of a fragment of the U1-A protein bound to stem-loop II of U1 snRNA (Oubridge et al. 1994), the U2- $\mathrm{A}^{\prime} / \mathrm{B}^{\prime \prime}$ heterodimer bound to U2 snRNA stem-loop IV (Price et al. 1998), the $15.5 \mathrm{~K}$ protein complexed with the 5' SL of U4 snRNA (Vidovic et al. 2000), and two heteromeric Sm protein dimers (Kambach et al. 1999b), yielded the first insights into the atomic structure of the spliceosomal snRNPs.

More recently, progress has been made in determining the atomic structure of RNA and/or protein fragments of the spliceosome that play important roles in splice site recognition (reviewed by Ritchie et al. 2009). For example, the structural basis for several binary interactions important during early recognition of the branch site or polypyrimidine tract has been elucidated. These include SF1 bound to a branch site RNA (Liu et al. 2001), U2AF65 bound to a polypyrimidine tract (Sickmier et al. 2006), U2AF65's RRM3 bound to an amino-terminal SF1 peptide (Selenko et al. 2003), a heterodimer of U2AF65 and U2AF35 (Kielkopf et al. 2001), and SF3b14a/p14 bound to a SF3b155 peptide (Schellenberg et al. 2006; Spadaccini et al. 2006). Although it cannot be ruled out that the structure of these complexes differs in the context of the spliceosome, the high resolution information obtained can potentially be used to map their position in EM structures of early spliceosomal complexes, provided the resolution of the latter is sufficient (i.e., $\sim 10 \AA$ or less) for integrating such structural information. Indeed, using its atomic structure information, the p14/SF3b155 peptide complex could be fitted into the 3D EM map of the SF3b complex (Schellenberg et al. 2006).

High resolution structures of functionally important proteins of the U4/U6.U5 tri-snRNP have also now been reported. The crystal structure of a portion of the U4 snRNP, consisting of the U4 snRNA 5' stem-loop complexed with the $15.5 \mathrm{~K}$ protein and part of the hPrp31 protein, was solved (Fig. 6A) (Liu et al. 2007). This study revealed the molecular mechanism underlying the ordered assembly pathway of the U4 snRNP, demonstrating that the $15.5 \mathrm{~K}$ protein and U4 snRNA form a composite RNP binding site for hPrp31, with $15.5 \mathrm{~K}$ additionally stabilizing the RNA in a conformation favourable for hPrp31 binding. Induced fit interactions are common for most RNA-protein complexes and the binding of Prp31 leads to pronounced structuring of the pentaloop of the U4 snRNA $5^{\prime}$ stem-loop (Fig. 6A).

Insights into the overall structure and mechanism of action the U5-associated $\mathrm{DExD} / \mathrm{H}$-box helicase Brr2 have also now been obtained. Brr2 contains two helicase domains (the second of which does not appear to be essential for its helicase activity), each comprised of two RecA-like modules followed by a Sec63-like domain of unknown function. Two groups have now solved the crystal structure of the C-terminal Sec63 domain of S. cerevisiae Brr2 and discovered similarities between two of its three subdomains and two structural modules of archaeal Hel308, a processive $3^{\prime}$ to $5^{\prime}$ DNA helicase involved in DNA repair (Pena et al. 2009; Zhang et al. 2009). Based on this information, the conservation of sequence throughout the remainder of these helicases, and additional functional data, both groups proposed a structural model for the amino-terminal, functional helicase domain of Brr2 that is analogous to the structure of Hel308. In the latter the Sec63-like domain is an integral component of the active site and is functionally connected to the two RecA-like domains by a winged helix module. The functional implication of the proposed structural organization of Brr2 is that, unlike other spliceosome associated DExH/D-box proteins, Brr2 may act in a more processive manner, which would likely be required to unwind the long stem regions of the U4/U6 duplex during the catalytic activation of the spliceosome. 
As discussed earlier, Prp8 is thought to play a key role in organizing the catalytic core of the spliceosome, and it contacts all of the reactive groups (i.e., the $5^{\prime}$ ss, $3^{\prime}$ ss, and BS) of the pre-mRNA substrate during splicing. Prp8 contains a centrally located RRM, thought to mediate Prp8-RNA interactions. The crystal structure of the carboxyl terminus of the S. cerevisiae (Pena et al. 2007) and Caenorhabditis elegans (Zhang et al. 2007) Prp8 protein revealed a Jab1/ MPN core domain, found in enzymes that remove ubiquitin from ubiquitinated proteins. However, in Prp8 the Jab1/MPN domain is interrupted by insertions and the metal binding site is impaired. As the carboxyl terminus of Prp8 binds both Brr2 and Snu114, it was proposed that this domain of Prp8 represents a pseudoenzyme converted into a protein-protein interaction platform (Pena et al. 2007).

The most intriguing structure to be elucidated recently is that of another domain of the Prp8 protein located just upstream of the Jab1/MPN domain. Three groups independently solved the structure of a $\sim 250$ amino acid domain of human and/or yeast Prp8 near its carboxyl terminus, which encompasses amino acids that contact the 5 'ss of the pre-mRNA (Pena et al. 2008; Ritchie et al. 2008; Yang et al. 2008). The structure revealed an aminoterminal subdomain with an RNase $\mathrm{H}$-like fold consisting of a five-stranded mixed $\beta$-sheet flanked by two $\alpha$-helices (Fig. 6B), but with a truncated RNase $\mathrm{H}$ active center. The RNase H-like domain was interrupted by the insertion of a $\beta$-hairpin (atypical for RNase $\mathrm{H}$-like enzymes) and was juxtaposed by a carboxy-terminal cluster of five helices (Fig. 6B). The RNaseH-like domain was shown to interact with a model RNA comprising portions of U2, U6, and the 5 'ss (Ritchie et al. 2008), which may mimic part of the activated snRNA/pre-mRNA network. Furthermore, point mutations targeting the apparent RNase $\mathrm{H}$-like active site residues had deleterious effects on cell viability (Pena et al. 2008; Ritchie et al. 2008; Yang et al. 2008). Taken together, these results suggest a role for Prp8's RNase-Hlike domain in the assembly and/or maintenance of the spliceosome's catalytic core, and raise the interesting possibility that Prp8 may even directly participate in the catalysis of splicing, for example by coordinating a $\mathrm{Mg}$ ion important for catalysis.

\section{CRYSTAL STRUCTURE OF THE HUMAN U1 SnRNP}

The recently reported crystal structure of an in vitro assembled U1 snRNP at $5.5 \AA$ resolution represents a milestone in understanding the 3D structure of a spliceosomal snRNP (Pomeranz-Krummel et al. 2009). The crystallized U1 snRNP contained the U1 RNA, the seven
Sm proteins (B, D1, D2, D3, E, F, and G), and part of the U1-C and U1-70K proteins, but lacked the U1-A protein. Because of the relatively low resolution (for a crystal structure), site-specific labeling of individual proteins was performed to unambiguously map their positions, and the generation of an atomic model was aided by prior knowledge of the structure of several of the U1-associated proteins and a solution structure model of the U1 snRNA. The U1 structure was completed by modeling the known structure of U1-A bound to stem-loop II of the U1 snRNA.

The U1 snRNA consists of four stem-loops (I-IV) and a short helix $(\mathrm{H})$. It forms a four-helix junction with two coaxially stacked helices (stem-loop 1/stem-loop 2 and stem loop $3 /$ Helix H) followed by the single-stranded Sm site which separates stem loop 4 from stem loops 1-3 and helix H (Pomeranz-Krummel et al. 2009) (Fig. 6C). This is consistent with the previously proposed structure of free U1 snRNA that was based on biochemical studies (Krol et al. 1990). The crystal structure also confirmed the heptameric ring model of the Sm core, which proposed that the Sm proteins form a seven-membered ring containing one copy of each Sm protein, in the order E, G, D3, B, D1, D2 and F, with the Sm site RNA-Sm protein contacts occurring on the inner surface of the proposed ring (Kambach et al. 1999b) (Fig. 6C). In addition, the crystal structure indicates that each Sm protein contacts one nucleotide of the U1 snRNA with the seven nucleotides of the Sm site (5-AUUUGUG-3') likely to interact with the Sm proteins E, G, D3, B, D1, D2 and F, respectively (PomeranzKrummel et al. 2009). This general arrangement of the Sm core is likely to be found in all other snRNPs that contain the Sm proteins. The U1-70K protein contacts stem loop 1 of the U1 snRNA, and its amino-terminus wraps around the Sm core and contacts the U1-C protein, nearly $180 \AA$ away from its RNA binding site (Fig. 6C). The amino-terminus of the U1-70K protein together with the carboxyl terminus of $\mathrm{SmD} 3$, create a binding pocket for the U1-C protein, which provides a structural basis for the previously observed dependence of U1-C binding on the amino terminus of the U1-70K protein. Previous biochemical studies revealed a role for U1-C in stabilizing the base pairing interaction of the U1 snRNA with the $5^{\prime} \mathrm{ss}$. In the U1 crystal structure, the 5'-end of the U1 RNA was partially base paired to an adjacent U1 RNA, mimicking the U1/5'ss duplex and thereby providing clues for how the U1 snRNA and U1-C might recognize the 5 'ss of the intron during early spliceosome assembly (Fig. 6C). A loop and helix of the zinc finger domain of the U1-C protein binds across the minor groove of this duplex, consistent with a role for U1-C in stabilizing the U1/5'ss duplex in early spliceosomal complexes. 
A
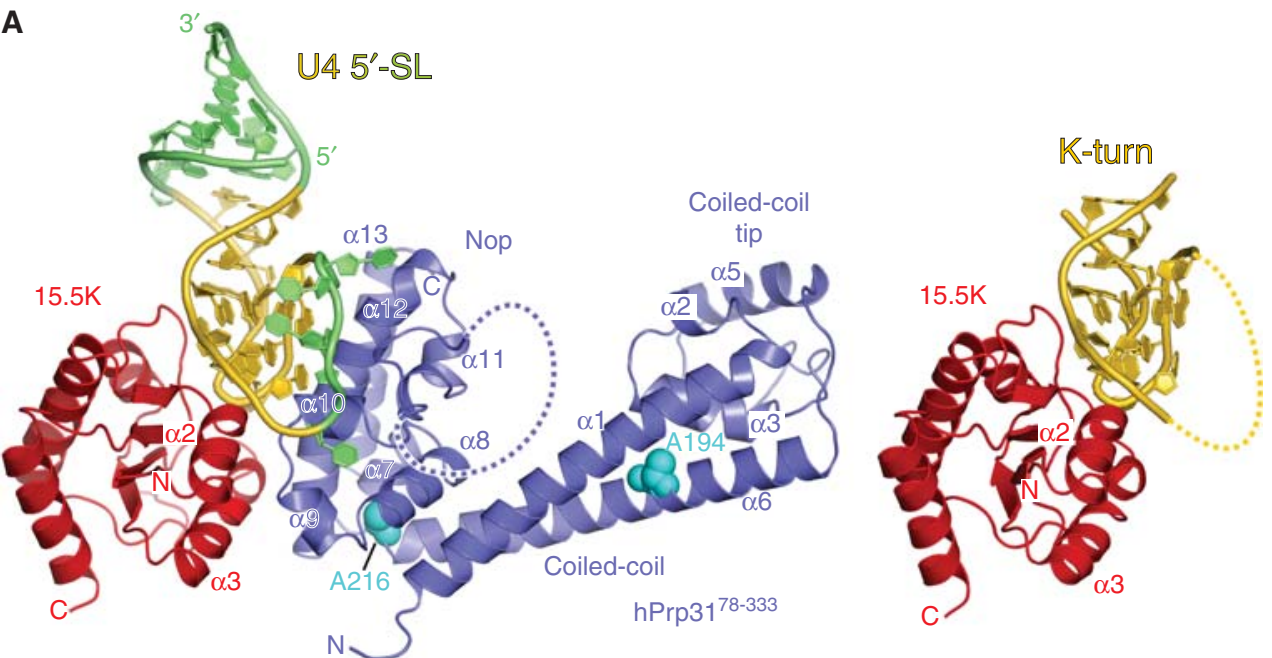

B

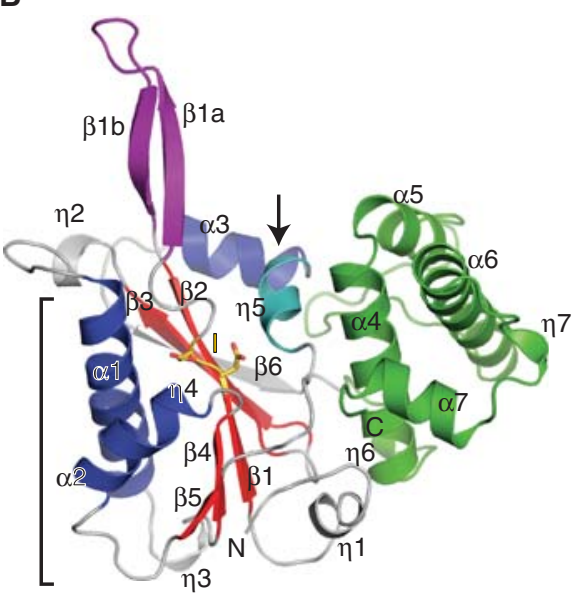

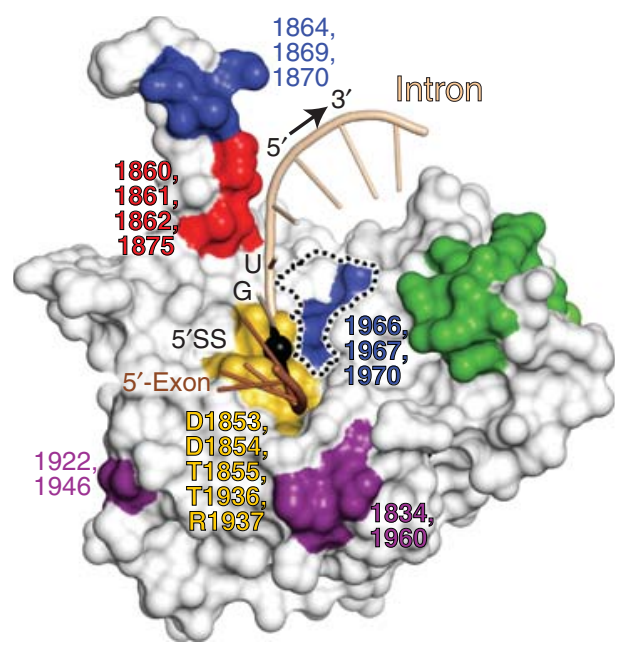

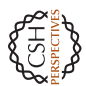

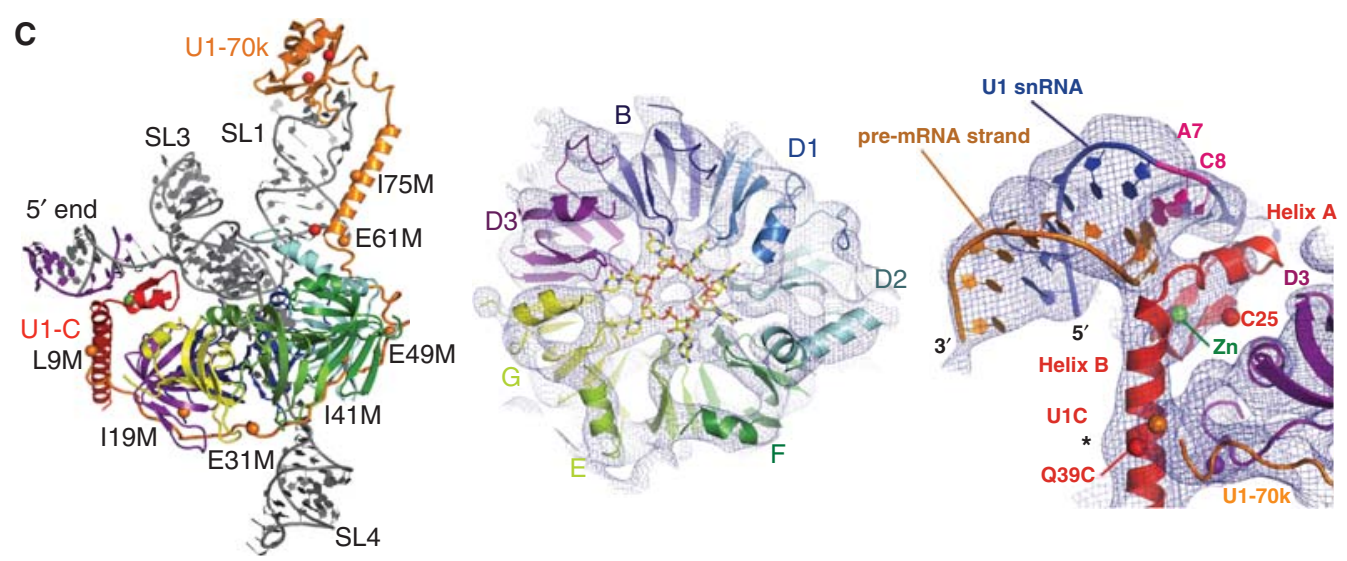

Figure 6. Structures of the U4 snRNA 5' stem-loop complexed with Prp31 and the $15.5 \mathrm{~K}$ protein, the RNAse H-like domain of Prp8, and the U1 snRNP. (A) Left, ribbon diagram of hPrp31 (residues 78-333)(purple) and the 15.5K protein (red) complexed with the human U4 snRNA 5'stem loop (nts 20-52) (gold and green). RNA elements absent in the 15.5K-U4 RNA binary complex (because of the shorter RNA used) (shown at right) are highlighted in green. A disordered loop of hPrp31 in the ternary complex and an unstructured region of the U4 pentaloop in the binary complex are indicated by a dashed lines. Mutations at positions A194 and A216 (shown as cyan-colored space-filling models) are linked to retinitis pigmentosa. (See facing page for legend). 
14 ELUCIDATION OF THE SPATIAL ORGANIZATION OF SPLICEOSOMAL COMPLEXES USING BIOCHEMICAL PROBES

Studies employing site-specifically tethered biochemical probes have demonstrated the power of this method for elucidating the spatial arrangement of spliceosomal components at different stages of the splicing process. For example, hydroxyl radical probing with Fe-BABE-tethered pre-mRNA revealed that the branchpoint and the $3^{\prime}$ ss are located within $20 \AA$ of the $5^{\prime}$ ss already in the E complex (Kent and MacMillan 2002). These data thus indicate that the pre-mRNA's $5^{\prime}$ ss, BS, and 3'ss are spatially preorganized in the E complex. In a more recent study, the organization of $\mathrm{U} 2$ relative to $\mathrm{U} 1$ and pre-mRNA in spliceosomal complexes was analyzed via site-directed hydroxyl radical probing with Fe-BABE tethered to the $5^{\prime}$ end of U2 snRNA (Dönmez et al. 2007). These studies revealed that functional regions (i.e., the $5^{\prime} \mathrm{ss}$, BS, and $3^{\prime} \mathrm{ss}$ ) of the pre-mRNA are located close to the $5^{\prime}$ end of $\mathrm{U} 2$ in both the $\mathrm{E}$ and A complexes. Furthermore, they showed that U2 is also positioned close to U1 in a defined orientation already in the E complex, and that their relative spatial organization remains largely unchanged during the E to A transition. Finally, hydroxyl radical probing with $\mathrm{Fe}-\mathrm{BABE}$ site-specifically tethered to the pre-mRNA 10 nts downstream of the 5 'ss revealed that the asymmetric bulge of the U6 ISL is in close proximity to the 5'ss/U6 ACAGAG box helix in the activated spliceosome (Rhode et al. 2006). These studies represent important first steps towards understanding the tertiary structure of the spliceosome's RNA-RNA and RNP networks.
In addition to the use of site-specifically introduced biochemical probes, ground work has now been laid to track structural rearrangements and the dynamics of proteinprotein and RNA-protein interactions within the spliceosome by introducing fluorescent probes into spliceosomal components for FRET analysis (Rino et al. 2008; Ellis et al. 2009), or by using single molecule approaches (Crawford et al. 2008; Guo et al. 2009). Most of these studies have been carried out in living cells where intermolecular interactions involving spliceosomal proteins are not limited to the spliceosome. In vitro, splicing reconstitution systems-for example as described above for S. cerevisiae (Warkocki et al. 2009)—are highly amenable for introducing fluorescently labelled proteins into in vitro assembled spliceosomes and tracking intermolecular interactions during activation and the catalytic steps of splicing via FRETor other fluorescence-based assays. Thus, in the near future fluorescence-based techniques may be more commonly used to elucidate the structural dynamics of the spliceosome.

\section{ELECTRON MICROSCOPY OF SPLICEOSOMAL COMPLEXES}

Because of its highly dynamic and complex nature, singleparticle cryo-electron microscopy is currently the method of choice to study the higher-order structure of the spliceosome. 2D EM views of various spliceosomal complexes isolated under physiological conditions from human, D. melanogaster and S. cerevesiae are now available (Deckert et al. 2006; Fabrizio et al. 2009; Herold et al. 2009). These studies reveal conservation of the overall size and shape of the pre-catalytic B complex (Fig. 7) and the catalytic C complex from various organisms, indicating that higher

Figure 6. (Continued) hPrp31 binds to one region of the composite binding platform formed by $15.5 \mathrm{~K}$ and the U4 snRNA by a lock-and-key type mechanism, and another region of the RNA via an induced fit mechanism. (Reprinted, with permission, from Liu et al. 2007 [ (C) AAAS].) (B) Ribbon diagram (left) and space filling model (right) of the S. cerevisiae Prp8 protein (residues 1827-2092). Left, the mixed $\beta$-sheet and two $\alpha$-helices typical of RNAse H domains are highlighted, red and purple, respectively. The Prp8-specific $\beta$-hairpin and $\alpha$-helices are colored magenta and green, respectively. Residues comprising the active site in RNAse H (corresponding to Asp1853 and Asp1854 in yeast Prp8) are indicated by sticks and the $3_{10}$ helix that is crosslinked to the $5^{\prime}$ splice site is highlighted cyan blue. Right, modeling of the pre-mRNA (exon and intron nucleotides, brown and beige, respectively and $5^{\prime}$ ss phosphate, black) into the Prp8 RNAse-like domain space filling model. Site of Prp 8 crosslinks to the $5^{\prime}$ ss is encompassed by a dashed line and the predicted active site, gold. The Brr 2 interacting region is shown in green. The sites of Prp 8 mutations (amino acid residue indicated) suppressing $5^{\prime}$ ss (blue), 3'ss (green), polypyrimidine tract (purple) and U4 cs1 (magenta) mutations are indicated. $(C)$ Left, ribbon diagram of the U1 snRNP containing the Sm proteins and the $70 \mathrm{~K}$ and C proteins. The U1 snRNA, with stem-loop (SL) 1, 3 and 4, and the $5^{\prime}$ end indicated, is shaded grey. Orange spheres indicate anomalous peaks from SeMet (introduced at the indicated amino acid position) in U1-70K. Middle, ribbon diagram of the Sm proteins (E, F, G, D1, D2, D3, B) and seven nucleotide Sm site RNA, with the experimental electron density map (contoured at $1 \sigma$ ). Right, Ribbon diagram with experimental electron density map (contoured at $1 \sigma$ ) of the interaction of the $5^{\prime}$ end of U1 snRNA with a neighboring complex (orange) which mimics the 5'ss of the pre-mRNA. (Reprinted, with permission, from Newman and Nagai 2010 [(C) Elsevier]; originally Pomeranz-Krummel et al. 2009 [ (C) Macmillan].) 
order interactions and the general spatial organization of each of these spliceosomal complexes is conserved between higher and lower eukaryotes.

The structures of the precatalytic B, activated B, and catalytically active $\mathrm{C}$ complexes appear to differ dramatically (at least at the $2 \mathrm{D}$ level). In a very recent study, the yeast $\mathrm{B}, \mathrm{B}^{\text {act }}$, and $\mathrm{C}$ complexes were affinity purified and their structure determined by single-particle electron cryomicroscopy (Fabrizio et al. 2009). A comparison of 2D class averages of these complexes revealed a maximum dimension of $\sim 400 \AA$ in each case (Fig. 7B). The morphology of the main projection images of $\mathrm{B}$ differed clearly from those of $\mathrm{B}^{\text {act }}$, which in turn differed from those of the $\mathrm{C}$ complex. The most pronounced differences were seen when comparing the B complex, which exhibits a triangular or rhombic shape in most class averages, with $\mathrm{B}^{\text {act }}$, whose main body is clearly more compact (Fig. 7B). The structural dynamics revealed by these studies are consistent with the compositional changes and RNP rearrangements occurring during the $\mathrm{B}$ to $\mathrm{B}^{\text {act }}$ and $\mathrm{B}^{\text {act }}$ to $\mathrm{C}$ transitions.
A structural change was also uncovered by EM studies of yeast spliceosomes during the conversion of $\mathrm{B}^{\text {act }}$ to $\mathrm{B}^{*}$, the catalytically active spliceosome formed after the ATPdependent action of Prp2 (Warkocki et al. 2009). Taken together, these results underscore the myriad of conformational changes that the spliceosome undergoes during its assembly, activation, and catalytic activity. They further suggest that, unlike the ribosome, a characteristic spliceosome structure does not exist, but rather because of its highly dynamic nature, its structure varies greatly throughout the splicing cycle.

\section{LOCALIZATION OF REGIONS OF THE PRE-mRNA IN THE SPLICEOSOME VIA EM}

To localize functionally important components of the spliceosome, two groups have now introduced tags into the pre-mRNA and mapped their position in the 2D EM structure of the spliceosomal C or B complex. In the first study, an RNA hairpin that binds the coliphage coat protein PP7

A
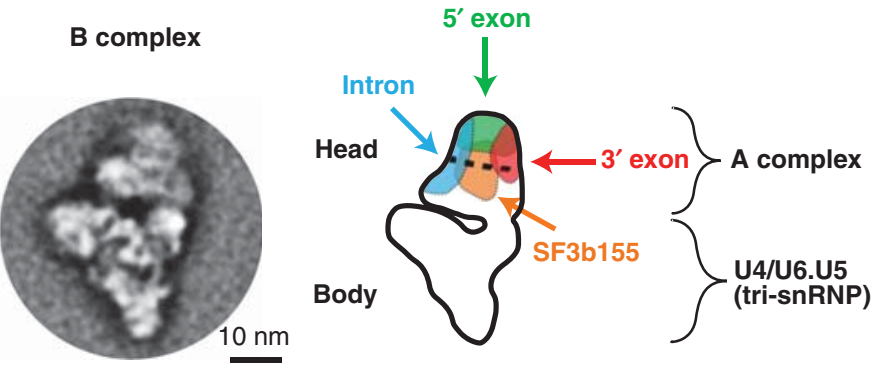

B
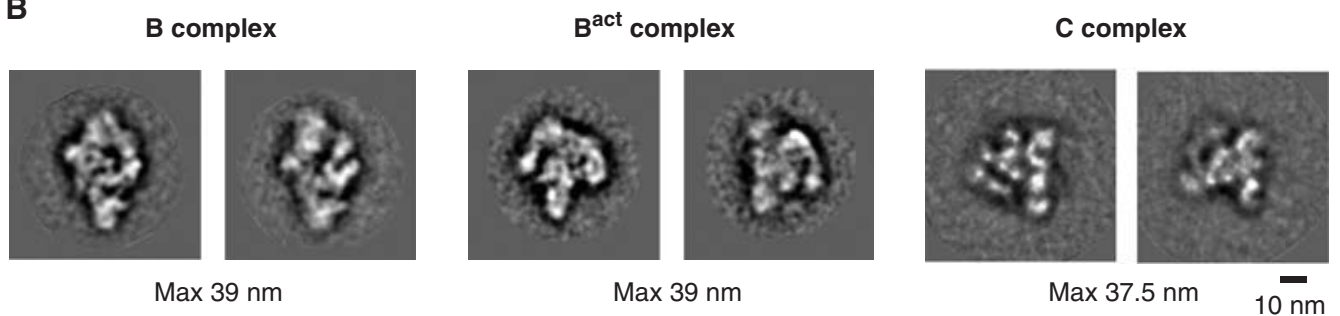

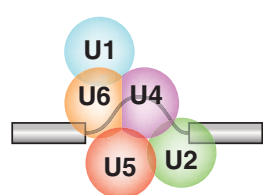

$40 S$

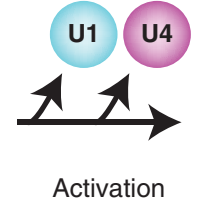

Activation

$\operatorname{Max} 39 \mathrm{~nm}$

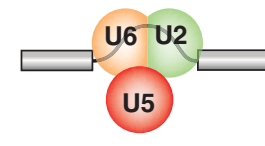

$45 S$

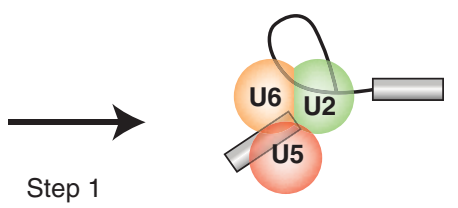

$40 \mathrm{~S}$

Figure 7. Structural dynamics of the yeast spliceosome as visualized by EM and localization of the pre-mRNA in the human B complex. (A) Class average of electron microscopy images of negatively stained, affinity-purified human B complexes (right). Sketch of the B complex showing regions where the $5^{\prime}$ exon, $3^{\prime}$ exon, intron and SF3b155 protein were mapped by immuno-EM, and the likely location of components of the A complex and tri-snRNP. (Adapted from Wolf et al. 2009 [(C) Nature Publishing Group].) (B) Electron microscopy of negatively-stained, affinitypurified S. cerevisiae $\mathrm{B}, \mathrm{B}^{\text {act }}$, and $\mathrm{C}$ complexes. Two prominent class averages of each complex are shown, with the maximum dimension indicated later. (Adapted, with permission, from Fabrizio et al. 2009 [C Elsevier].) 
was introduced into either the $5^{\prime}$ or $3^{\prime}$ exon of a pre-mRNA substrate (Alcid and Jurica 2008). After binding a PP7/ $\mathrm{dnaN}$ fusion protein, $\mathrm{C}$ complexes were allowed to form in nuclear extract, and were then affinity-selected and analyzed by single particle EM. Localization of the $5^{\prime}$ versus $3^{\prime}$ tags in 2D EM images revealed that the $5^{\prime}$ and $3^{\prime}$ exons are in close proximity in the C complex. In a second study, MS2 binding sites were introduced into either the $5^{\prime}$ or $3^{\prime}$ exon or the intron of the substrate, and were then bound by an MS2-MBP fusion protein. B complexes assembled in vitro on the pre-bound substrate were subsequently affinity selected and analyzed by EM (Wolf et al. 2009). The positions of the $5^{\prime}$ and $3^{\prime}$ exon and intron, were mapped after binding anti-MBP antibodies and labeling them with colloidal gold. These studies revealed that both exons and the intron are located near each other in the head domain of the B complex (Fig. 7A). Additional immuno-labeling with antibodies against SF3b155, indicated that the latter protein (and as a consequence the U2 snRNP) is also localized in the head region of the B complex (Fig. 7A). These studies represent important first steps toward mapping functionally important sites in the spliceosome.

\section{3D STRUCTURES OF THE SPLICEOSOME OBTAINED BY EM}

EM analyses of the 3D structure of the spliceosome have been hampered, primarily by the highly dynamic and labile nature of the spliceosome, which has resulted in difficulties in purifying defined, biochemically homogeneous, spliceosomal complexes that are structurally stable. By performing single-particle electron cryomicroscopy, 3D structures at a resolution of 30-40 $\AA$ were reported for the human spliceosomal $\mathrm{B}$ and $\mathrm{C}$ complex, both affinity-purified from splicing extracts under stringent conditions in the presence of heparin (reviewed by Stark and Lührmann 2006). B $\Delta$ U1 exhibited a triangular main body with a globular head domain and a maximum dimension of $370 \AA$ (Bohringer et al. 2004), whereas the $C$ complex possessed an asymmetric shape with three main subdomains and a maximum dimension of $270 \AA$ (Jurica et al. 2004). At the current level of resolution, it is difficult to conclusively map the relative positions of the snRNP complexes within the spliceosome. Nonetheless, a comparison of the structure of the human U4/U6.U5 tri-snRNP with that of B $\Delta \mathrm{U} 1$, strongly suggested that the tri-snRNP is located in the lower triangular domain of $\mathrm{B} \Delta \mathrm{U} 1$ and, as a consequence, that the $\mathrm{U} 2 \mathrm{snRNP}$ must be localized in the upper globular domain (Boehringer et al. 2004; Sander et al. 2006). The 3D structure of the spliceosomal A complex, purified under physiological conditions, has also been elucidated (Behzadnia et al. 2007). It possesses a main globular body $\sim 205 \AA \times 195$
$\AA \times 150 \AA$ in size, from which several smaller elements protrude. Due to the low resolution of the 3D structure ( $\sim 40-50 \AA$ ), it was not possible to localize A complex components, such as SF3b, whose 3D structure is known. In addition to these in vitro assembled spliceosomal complexes, the 3D structure of in vivo assembled human spliceosomes (whose assembly/functional stage is presently not clear) (Azubel et al. 2004), and in vivo assembled Schizosaccharomyces pombe spliceosomal complexes containing U2, U5, and U6 (Ohi et al. 2007), have also been reported.

Higher resolution 3D EM structures of the spliceosome await improvements in sample preparation and also in image analysis (discussed by Lührmann and Stark 2009). A recent step in this direction was the development of a mild chemical fixation method (termed Grafix), that has considerably improved sample quality and contrast, such that EM images suitable for a reliable 3D structure reconstruction could be obtained by cryo-EM, even in the absence of stain (Kastner et al. 2008). Reducing the compositional heterogeneity of a given complex and obtaining samples where the vast majority are stalled at a specific conformational stage should also lead to improvements in resolution. In this respect, yeast spliceosomes-which are less complex and contain fewer substoichiometrically associated proteins - and which can be stalled at more precise steps of the splicing reaction using temperature-sensitive $(t s)$ mutants of the various $\mathrm{DExH} / \mathrm{D}$-box spliceosomal proteins, appear to be ideal candidates for obtaining higher resolution images.

\section{SUMMARY}

Much progress has been made in recent years towards understanding the structure and function of the spliceosome. Both its conformation and composition have proven to be highly dynamic. Despite the hurdles generated by its dynamic nature, a clearer picture of the order and nature of the intricate rearrangements within the spliceosome and their contribution to its function, is slowly emerging. However, answers to a number of questions, foremost the precise nature of its active site, await the generation of a high-resolution structure of the spliceosome.

\section{ACKNOWLEDGMENTS}

We are grateful to Berthold Kastner, Patrizia Fabrizio, Holger Stark, Markus Wahl and Elmar Wolf for providing figures. We thank Patrizia Fabrizio, Klaus Hartmuth, and Markus Wahl for constructive comments. We apologize to those of our colleagues who were not cited due to space limitations. This work was funded by grants from the DFG, 
the European Commission (EURASNET-518238), Fonds der Chemischen Industrie and the Ernst Jung Stiftung to Reinhard Lührmann.

\section{REFERENCES}

Abelson J. 2008. Is the spliceosome a ribonucleoprotein enzyme? Nat Struct Mol Biol 15: 1235-1237.

Alcid EA, Jurica MS. 2008. A protein-based EM label for RNA identifies the location of exons in spliceosomes. Nat Struct Mol Biol 15: 213-215.

Aronova A, Bacíková D, Crotti LB, Horowitz DS, Schwer B. 2007. Functional interactions between Prp8, Prp18, Slu7, and U5 snRNA during the second step of pre-mRNA splicing. RNA 13: 1437-1444.

Ast G. 2004. How did alternative splicing evolve? Nat Rev 5: 773-782.

Azubel M, Wolf SG, Sperling J, Sperling R. 2004. Three-dimensional structure of the native spliceosome by cryo-electron microscopy. Mol Cell 15: 833-839.

Bartels C, Klatt C, Lührmann R, Fabrizio P. 2002. The ribosomal translocase homologue Snu114p is involved in unwinding U4/U6 RNA during activation of the spliceosome. EMBO Rep 3: 875-880.

Behzadnia N, Golas M, Hartmuth K, Sander B, Kastner B, Deckert J, Dube P, Will C, Urlaub H, Stark H, Lührmann R. 2007. Composition and three-dimensional EM structure of double affinity-purified, human prespliceosomal A complexes. EMBO J 26: 1737-1748.

Bellare P, Kutach AK, Rines AK, Guthrie C, Sontheimer EJ. 2006. Ubiquitin binding by a variant Jabl/MPN domain in the essential premRNA splicing factor Prp8p. RNA 12: 292-302.

Bellare P, Small EC, Huang X, Wohlschlegel JA, Staley JP, Sontheimer EJ. 2008. A role for ubiquitin in the spliceosome assembly pathway. Nat Struct Mol Biol 15: 444-451.

Berget SM. 1995. Exon recognition in vertebrate splicing. Mol Cell Biol 270: $2411-2414$.

Bessonov S, Anokhina M, Will CL, Urlaub H, Lührmann R. 2008. Isolation of an active step 1 spliceosome and composition of its RNP core. Nature 452: 846-850.

Black DL. 2003. Mechanisms of alternative pre-messenger RNA splicing. Annu Rev Biochem 72: 291-336.

Böhringer D, Makarov EM, Sander B, Makarova OV, Kastner B, Lührmann R, Stark H. 2004. Three-dimensional structure of a precatalytic human spliceosomal complex B. Nat Struct Mol Biol 11: $463-468$.

Bonnal S, Martinez C, Forch P, Bachi A, Wilm M, Valcárcel J. 2008. RBM5/Luca-15/H37 regulates Fas alternative splice site pairing after exon definition. Mol Cell 32: 81-95.

Brenner TJ, Guthrie C. 2005. Genetic analysis reveals a role for the C terminus of the Saccharomyces cerevisiae GTPase Snu114 during spliceosome activation. Genetics 170: 1063-1080.

Brow DA. 2002. Allosteric cascade of spliceosome activation. Annu Rev Genet 36: 333-360.

Burge CB, Tuschl T, Sharp PA. 1999. Splicing of Precursors to mRNAs by the Spliceosomes. In The RNA world Second edition (ed. R.F. Gesteland et al.), pp. 525-560. Cold Spring Harbor Laboratory Press, Cold Spring Harbor, New York.

Burgess SM, Guthrie C. 1993a. A mechanism to enhance mRNA splicing fidelity: The RNA-dependent ATPase Prp16 governs usage of a discard pathway for aberrant lariat intermediates. Cell 73: 1377-1391.

Burgess SM, Guthrie C. 1993b. Beat the clock: Paradigms for NTPases in the maintenance of biological fidelity. Trends Biochem Sci 18: 381-384.

Cao W, Jamison SF, Garcia-Blanco MA. 1997. Both phosphorylation and dephosphorylation of ASF/SF2 are required for pre-mRNA splicing in vitro. RNA 3: 1456-1467.
Chan SP, Cheng SC. 2005. The Prp19-associated complex is required for specifying interactions of U5 and U6 with pre-mRNA during spliceosome activation. J Biol Chem 280: 31190-31199.

Chan SP, Kao DI, Tsai WY, Cheng SC. 2003. The Prp19p-associated complex in spliceosome activation. Science 302: 279-282.

Chen M, Manley JL. 2009. Mechanisms of alternative splicing regulation: Insights from molecular and genomics approaches. Nat Rev Mol Cell Biol 10: 741-754.

Chen JY, Stands L, Staley JP, Jackups RR Jr, Latus LJ, Chang TH. 2001. Specific alterations of U1-C protein or U1 small nuclear RNA can eliminate the requirement of Prp28p, an essential DEAD box splicing factor. Mol Cell 7: 227-232.

Chiu YF, Liu YC, Chiang TW, Yeh TC, Tseng CK, Wu NY, Cheng SC. 2009. Cwc25 is a novel splicing factor required after Prp2 and Yju2 to facilitate the first catalytic reaction. Mol Cell Biol 29: 5671-5678.

Choudhary C, Kumar C, Gnad F, Nielsen ML, Rehman M, Walther TC, Olsen JV, Mann M. 2009. Lysine acetylation targets protein complexes and co-regulates major cellular functions. Science 325: 834-840.

Clark TA, Sugnet CW, Ares M Jr. 2002. Genomewide analysis of mRNA processing in yeast using splicing-specific microarrays. Science 296: 907-910.

Crawford DJ, Hoskins AA, Friedman LJ, Gelles J, Moore MJ. 2008. Visualizing the splicing of single pre-mRNA molecules in whole cell extract. RNA 14: $170-179$.

Crotti LB, Bacíková D, Horowitz DS. 2007. The Prp18 protein stabilizes the interaction of both exons with the U5 snRNA during the second step of pre-mRNA splicing. Genes Dev 21: 1204-1216.

Deckert J, Hartmuth K, Böhringer D, Behzadnia N, Will CL, Kastner B, Stark H, Urlaub H, Lührmann R. 2006. Protein composition and electron microscopy structure of affinity-purified human spliceosomal B complexes isolated under physiological conditions. Mol Cell Biol 26: $5528-5543$.

Dönmez G, Hartmuth K, Kastner B, Will CL, Lührmann R. 2007. The 5' end of $\mathrm{U} 2$ snRNA is in close proximity to $\mathrm{U} 1$ and functional sites of the pre-mRNA in early spliceosomal complexes. Mol Cell 25: 399-411.

Deutsch M, Long M. 1999. Intron-exon structures of eukaryotic model organisms. Nucleic Acids Res 27: 3219-3228.

Ellis JD, Llères D, Denegri M, Lamond AI, Cáceres JF. 2008. Spatial mapping of splicing factor complexes involved in exon and intron definition. J Cell Biol 181: 921-934.

Fabrizio P, Dannenberg J, Dube P, Kastner B, Stark H, Urlaub H, Lührmann R. 2009. The evolutionary conserved core design of the catalytic activation step of the yeast spliceosome. Mol Cell 36: 593-608.

Fox-Walsh KL, Dou Y, Lam BJ, Hung SP, Baldi PF, Hertel KJ. 2005. The architecture of pre-mRNAs affects mechanisms of splice-site pairing. Proc Natl Acad Sci 102: 16176-16181.

Golas MM, Sander B, Will CL, Lührmann R, Stark H. 2003. Molecular architecture of the multiprotein splicing factor SF3b. Science 300: 980-984.

Golas MM, Sander B, Will CL, Lührmann R, Stark H. 2005. Major conformational change in the protein complex SF3b upon integration into the spliceosomal U11/U12 di-snRNP as revealed by electron cryomicroscopy. Mol Cell 17: 869-883.

Grainger RJ, Beggs JD. 2005. Prp8 protein: At the heart of the spliceosome. RNA 11: 533-557.

Guo Z, Karunatilaka KS, Rueda D. 2009. Single-molecule analysis of protein-free U2-U6 snRNAs. Nat Struct Mol Biol 16: 1154-1159.

Häcker I, Sander B, Golas MM, Wolf E, Karagoez E, Kastner B, Stark H, Fabrizio P, Lührmann R. 2008. Localization of Prp8, Brr2, Snu114 and U4/U6 proteins in the yeast tri-snRNP by electron microscopy. Nat Struct Mol Biol 15: 1206-1212.

Herold N, Will CL, Wolf E, Kastner B, Urlaub H, Lührmann R. 2009. Conservation of the protein composition and electron microscopy structure of Drosophila melanogaster and human spliceosomal complexes. Mol Cell Biol 29: 281-301. 
Hilliker AK, Mefford MA, Staley JP. 2007. U2 toggles iteratively between the stem IIa and stem IIc conformations to promote pre-mRNA splicing. Genes Dev 21: 821-834.

Hoffman BE, Grabowski PJ. 1992. U1 targets an essential splicing factor, $\mathrm{U} 2 \mathrm{AF} 65$, to the $3^{\prime}$ splice site by a network of interactions spanning the exon. Genes Dev 6: 2554-2568.

House AE, Lynch KW. 2006. An exonic splicing silencer represses spliceosome assembly after ATP-dependent exon recognition. Nat Struct Mol Biol 13: 937-944.

Jacquier A. 1990. Self-splicing group II and nuclear pre-mRNA introns: how similar are they? Trends Biochem Sci 15: 351-354.

Jurica MS, Moore MJ. 2003. Pre-mRNA splicing: Awash in a sea of proteins. Mol Cell 12: 5-14.

Jurica MS, Sousa D, Moore MJ, Grigorieff N. 2004. Three-dimensional structure of C complex spliceosomes by electron microscopy. Nat Struct Mol Biol 11: 265-269.

Kambach C, Walke S, Nagai K. 1999a. Structure and assembly of the spliceosomal small nuclear ribonucleoprotein particles. Curr Opin Struct Biol 9: 222-230.

Kambach C, Walke S, Young R, Avis JM, de la Fortelle E, Raker VA, Lührmann R, Li J, Nagai K. 1999b. Crystal structures of two Sm protein complexes and their implications for the assembly of the spliceosomal snRNPs. Cell 96: 375-387.

Karaduman R, Dube P, Stark H, Fabrizio P, Kastner B, Lührmann R. 2008. Structure of yeast U6 snRNPs: Arrangement of Prp24p and the LSm complex as revealed by electron microscopy. RNA 14: $2528-2537$.

Kastner B, Fischer N, Golas M, Sander B, Dube P, Boehringer D, Hartmuth K, Deckert J, Hauer F, Wolf E, et al. 2008. GraFix: Sample preparation for single-particle electron cryomicroscopy. Nat Methods 5: $53-55$.

Keating KS, Toor N, Perlman PS, Pyle AM. 2010. A structural analysis of the group II intron active site and implications for the spliceosome. RNA 16: 1-9.

Kent OA, MacMillan AM. 2002. Early organization of pre-mRNA during spliceosome assembly. Nat Struct Biol 9: 576-581.

Kielkopf CL, Rodionova NA, Green MR, Burley SK. 2001. A novel peptide recognition mode revealed by the $\mathrm{X}$-ray structure of a core U2AF35/U2AF65 heterodimer. Cell 106: 595-605.

Kistler AL, Guthrie C. 2001. Deletion of MUD2, the yeast homolog of U2AF65, can bypass the requirement for Sub2, an essential spliceosomal ATPase. Genes Dev 15: 42-49.

Konarska MM, Query CC. 2005. Insights into the mechanisms of splicing: More lessons from the ribosome. Genes Dev 19: 2255-2260.

Konarska MM, Vilardell J, Query CC. 2006. Repositioning of the reaction intermediate within the catalytic center of the spliceosome. Mol Cell 21: $543-553$.

Krol A, Westhof E, Bach M, Lührmann R, Ebel JP, Carbon P. 1990. Solution structure of human U1 snRNA. Derivation of a possible threedimensional model. Nucleic Acids Res 18: 3803-3811.

Kuhn AN, Van Santen M A, Schwienhorst A, Urlaub H, Lührmann R. 2009. Stalling of spliceosome assembly at distinct stages by smallmolecule inhibitors of protein acetylation and deacetylation. RNA 15: $153-175$.

Lim SR, Hertel KJ. 2004. Commitment to splice site pairing coincides with A complex formation. Mol Cell 15: 477-483.

Liu L, Query CC, Konarska MM. 2007. Opposing classes of prp8 alleles modulate the transition between the catalytic steps of pre-mRNA splicing. Nat Struct Mol Biol 14: 519-526.

Liu YC, Chen HC, Wu NY, Cheng SC. 2007. A novel splicing factor, Yju2, is associated with NTC and acts after Prp2 in promoting the first catalytic reaction of pre-mRNA splicing. Mol Cell Biol 27: 403-5413.

Liu S, Li P, Dybkov O, Nottrott S, Hartmuth K, Lührmann R, Carlomagno T, Wahl MC. 2007. Binding of the human Prp31 nop domain to a composite RNA-protein platform in U4 snRNP. Science 316: 115-120.

Liu Z, Luyten I, Bottomley MJ, Messias AC, Houngninou-Molango S, Sprangers R, Zanier K, Krämer A, Sattler M. 2001. Structural basis for recognition of the intron branch site RNA by splicing factor 1 . Science 294: 1098-1102.

Lührmann R, Stark H. 2009. Structural mapping of spliceosomes by electron microscopy. Curr Opin Struct Biol 19: 96-102.

Madhani HD, Guthrie C. 1992. A novel base-pairing interaction between U2 and U6 snRNAs suggests a mechanism for the catalytic activation of the spliceosome. Cell 71: 803-817.

Madhani HD, Guthrie C. 1994. Genetic interactions between the yeast RNA helicase homolog Prp16 and spliceosomal snRNAs identify candidate ligands for the Prp16 RNA-dependent ATPase. Genetics 137: 677-687.

Maeder C, Kutach AK, Guthrie C. 2009. ATP-dependent unwinding of U4/U6 snRNAs by the Brr2 helicase requires the C terminus of Prp8. Nat Struct Mol Biol 16: 42-48.

Maniatis T, Reed R. 2002. An extensive network of coupling among gene expression machines. Nature 416: 499-506.

Mathew R, Hartmuth K, Moehlmann S, Urlaub H, Ficner R, Lührmann R. 2008. Phosphorylation of human PRP28 by SRPK2 is required for integration of the U4/U6-U5 tri-snRNP into the spliceosome. Nat Struct Mol Biol 15: 435-443.

Matlin AJ, Moore MJ. 2007. Spliceosome assembly and composition. Adv Exp Med Biol 623: 14-35.

Matlin AJ, Clark F, Smith CW. 2005. Understanding alternative splicing: Towards a cellular code. Nat Rev Mol Cell Biol 6: 386-398.

Mayas RM, Maita H, Staley JP. 2006. Exon ligation is proofread by the DExD/H-box ATPase Prp22p. Nat Struct Mol Biol 13: 482-490.

Mefford MA, Staley JP. 2009. Evidence that U2/U6 helix I promotes both catalytic steps of pre-mRNA splicing and rearranges in between these steps. RNA 15: 1386-1397.

Misteli T. 1999. RNA splicing: What has phosphorylation got to do with it? Curr Biol 9: R198-200.

Moore MJ, Query CC, Sharp PA. 1993. Splicing of precursors to mRNA by the spliceosome. In RNA World (ed. R.F. Gesteland, J.F. Atkins), pp. 303-357. Cold Spring Harbor Labratory Press, Cold Spring Harbor, New York.

Nilsen TW. 1998. RNA-RNA interactions in nuclear pre-mRNA splicing. In RNA Structure and Function (ed. R.W. Simons, M. GrunbergManago), pp. 279-308. Cold Spring Harbor Press, Cold Spring Harbor.

Nilsen TW, Graveley BR. 2010. Expansion of the eukaryotic proteome by alternative splicing. Nature 463: 457-463.

Novoyatleva T., Tang Y, Rafalska I, Stamm S. 2006. Pre-mRNA missplicing as a cause of human disease. Prog Mol Subcell Biol 44: 27-46.

Ohi MD, Ren L, Wall JS, Gould KL, Walz T. 2007. Structural characterization of the fission yeast U5.U2/U6 spliceosome complex. Proc Natl Acad Sci 104: 3195-3200.

Oubridge C, Ito N, Evans PR, Teo CH, Nagai K. 1994. Crystal structure at 1.92 A resolution of the RNA-binding domain of the U1A spliceosomal protein complexed with an RNA hairpin. Nature 372: 432-438.

Pandit S, Lynn B, Rymond BC. 2006. Inhibition of a spliceosome turnover pathway suppresses splicing defects. Proc Natl Acad Sci 103: $13700-13705$.

Park JW, Parisky K, Celotto AM, Reenan RA, Graveley BR. 2004. Identification of alternative splicing regulators by RNA interference in Drosophila. Proc Natl Acad Sci 101: 15974-15979.

Patel AA, Steitz JA. 2003. Splicing double: Insights from the second spliceosome. Nat Rev Mol Cell Biol 4: 960-970.

Pena V, Liu S, Bujnicki JM, Lührmann R, Wahl MC. 2007. Structure of a multipartite protein-protein interaction domain in splicing factor Prp8 and its link to retinitis pigmentosa. Mol Cell 25: 615-624.

Pena V, Rozov A, Fabrizio P, Lührmann R, Wahl MC. 2008. Structure and function of an RNase $\mathrm{H}$ domain at the heart of the spliceosome. EMBO J 27: 2929-2940.

Pena V, Mozaffari SJ, Fabrizio P, Orlowski J, Bujnicki JM, Lührmann R, Wahl MC. 2009. Common design principles in the spliceosomal RNA helicase Brr2 and in the Hel308 DNA helicase. Mol Cell 35: 454-466. 
Perriman RJ, Ares M Jr. 2007. Rearrangement of competing U2 RNA helices within the spliceosome promotes multiple steps in splicing. Genes Dev 21: 811-820.

Pleiss JA, Whitworth GB, Bergkessel M, Guthrie C. 2007. Transcript specificity in yeast pre-mRNA splicing revealed by mutations in core spliceosomal components. PLoS Biol 5: e90.

Pomeranz-Krummel DA, Oubridge C, Leung AK, Li J, Nagai K. 2009. Crystal structure of human spliceosomal U1 snRNP at 5.5 A resolution. Nature 458: 475-480.

Price SR, Evans PR, Nagai K. 1998. Crystal structure of the spliceosomal U2B"-U2A' protein complex bound to a fragment of $\mathrm{U} 2$ small nuclear RNA. Nature 394: 645-650.

Query CC, Konarska MM. 2004. Suppression of multiple substrate mutations by spliceosomal prp8 alleles suggests functional correlations with ribosomal ambiguity mutants. Mol Cell 14: 343-354.

Reed R 2000. Mechanisms of fidelity in pre-mRNA splicing. Curr Opin Cell Biol 12: 340-345.

Rhode BM, Hartmuth K, Westhof E, Lührmann R. 2006. Proximity of conserved U6 and U2 snRNA elements to the $5^{\prime}$ splice site region in activated spliceosomes. EMBO J 25: 2475-2486.

Rino J, Desterro JM, Pacheco TR, Gadella TW Jr, Carmo-Fonseca M. 2008. Splicing factors SF1 and U2AF associate in extraspliceosomal complexes. Mol Cell Biol 28: 3045-3057.

Ritchie DB, Schellenberg MJ, Macmillan AM. 2009. Spliceosome structure: Piece by piece. Biochim Biophys Act 1789: 624-633.

Ritchie DB, Schellenberg MJ, Gesner EM, Raithatha SA, Stuart DT, Macmillan AM. 2008. Structural elucidation of a PRP8 core domain from the heart of the spliceosome. Nat Struct Mol Biol 15: 1199-1205.

Sashital DG, Cornilescu G, McManus CJ, Brow DA, Butcher SE. 2004. U2-U6 RNA folding reveals a group II intron-like domain and a fourhelix junction. Nat Struct Mol Biol 11: 1237-1242.

Sander B, Golas MM, Makarov EM, Brahms H, Kastner B, Lührmann R, Stark H. 2006. Organization of the core spliceosomal components U5 snRNA loop I and U4/U6 di-snRNP within the U4/U6.U5 tri-snRNP as revealed by 3D electron microscopy. Mol Cell 24: 267-278.

Schellenberg MJ, Edwards RA, Ritchie DB, Kent OA, Golas MM, Stark H, Lührmann R, Glover JNM, MacMilan AM. 2006. Crystal structure of a core spliceosomal protein interface. Proc Natl Acad Sci 103: $1266-1271$.

Schneider M, Hsiao HH, Will CL, Giet R, Urlaub H, Lührmann R. 2010a. Human PRP4 kinase is required for stable tri-snRNP association during spliceosomal B complex formation. Nat Struct Mol Biol 17: 216-221.

Schneider M, Will CL, Anokhina M, Tazi J, Urlaub U, Lührmann R. 2010b. Exon definition complexes contain the tri-snRNP and can be directly converted into B-like pre-catalytic splicing complexes. $\mathrm{Mol}$ Cell 38: 223-235.

Schwer B. 2008. A conformational rearrangement in the spliceosome sets the stage for Prp22-dependent mRNA release. Mol Cell 30: $743-754$

Selenko P, Gregorovic G, Sprangers R, Stier G, Rhani Z, Krämer A, Sattler M. 2003. Structural basis for the molecular recognition between human splicing factors U2AF65 and SF1/mBBP. Mol Cell 11: 965-976.

Sharma S, Kohlstaedt LA, Damianov A, Rio DC, Black DL. 2008. Polypyrimidine tract binding protein controls the transition from exon definition to an intron defined spliceosome. Nat Struct Mol Biol 15: $183-191$.

Shen H, Green MR. 2004. A pathway of sequential arginine-serine-rich domain-splicing signal interactions during mammalian spliceosome assembly. Mol Cell 16: 363-373.

Shen H, Green MR. 2006. RS domains contact splicing signals and promote splicing by a common mechanism in yeast through humans. Genes Dev 20: 1755-1765.

Shen H, Green MR. 2007. RS domain-splicing signal interactions in splicing of U12-type and U2-type introns. Nat Struct Mol Biol 14: $597-603$
Shen H, Zheng X, Shen J, Zhang L, Zhao R, Green MR. 2008. Distinct activities of the DExD/H-box splicing factor hUAP56 facilitate stepwise assembly of the spliceosome. Genes Dev 22: 1796-1803.

Shi Y, Reddy B, Manley JL. 2006. PP1/PP2A phosphatases are required for the second step of pre-mRNA splicing and target specific snRNP proteins. Mol Cell 23: 819-829.

Sickmier EA, Frato KE, Shen H, Paranawithana SR, Green MR, Kielkopf CL. 2006. Structural basis for polypyrimidine tract recognition by the essential pre-mRNA splicing factor U2AF65. Mol Cell 23: 49-59.

Silverman EJ, Maeda A, Wei J, Smith P, Beggs JD, Lin RJ. 2004. Interaction between a G-patch protein and a spliceosomal DEXD/H-box ATPase that is critical for splicing. Mol Cell Biol 24: 10101-10110.

Small EC, Leggett SR, Winans AA, Staley JP. 2006. The EF-G-like GTPase Snu116p regulates spliceosome dynamics mediated by Brr2p, a DExD/H box ATPase. Mol Cell 23: 389-399.

Smith DJ, Konarska MM. 2009a. Identification and characterization of a short 2';-3' bond-forming ribozyme. RNA 15: 8-13.

Smith DJ, Konarska MM. 2009b. A critical assessment of the utility of protein-free splicing systems. RNA 15: 1-3.

Smith CW, Valcárcel J. 2000. Alternative pre-mRNA splicing: The logic of combinatorial control. Trends Biochem Sci 25: 381-388.

Smith DJ, Query CC, Konarska MM. 2007. trans-splicing to spliceosomal U2 snRNA suggests disruption of branch site-U2 pairing during premRNA splicing. Mol Cell 26: 883-890.

Smith DJ, Query CC, Konarska MM. 2008. "Nought may endure but mutability": Spliceosome dynamics and the regulation of splicing. Mol Cell 30: 657-666.

Soret J, Tazi J. 2003. Phosphorylation-dependent control of the premRNA splicing machinery. Prog Mol Subcell Biol 31: 89-126.

Spadaccini R, Reidt U, Dybkov O, Will C, Frank R, Stier G, Corsini L, Wahl MC, Lührmann R, Sattler M. 2006. Biochemical and NMR analyses of a SF3b155-p14-U2AF-RNA interaction network involved in branch point definition during pre-mRNA splicing. RNA 12: $410-425$.

Stevens SW, Ryan DE, Ge HY, Moore RE, Young MK, Lee TD, Abelson J. 2002. Composition and functional characterization of the yeast spliceosomal penta-snRNP. Mol Cell 9: 31-44.

Staley JP, Guthrie C. 1998. Mechanical devices of the spliceosome: Motors, clocks, springs, and things. Cell 92: 315-326.

Staley JP, Guthrie C. 1999. An RNA switch at the $5^{\prime}$ splice site requires ATP and the DEAD box protein Prp28p. Mol Cell 3: 55-64.

Staley JP, Woolford JL Jr. 2009. Assembly of ribosomes and spliceosomes: Complex ribonucleoprotein machines. Curr Opin Cell Biol 21: $109-118$

Stark H, Lührmann R. 2006. Electron cryomicroscopy of spliceosomal components. Ann Rev Biophy Biomol Struct 35: 435-457.

Stark H, Dube P, Luhrmann R, Kastner B. 2001. Arrangement of RNA and proteins in the spliceosomal U1 small nuclear ribonucleoprotein particle. Nature 409: 539-542.

Sun JS, Manley JL. 1995. A novel U2-U6 snRNA structure is necessary for mammalian mRNA splicing. Genes Dev 9: 843-854.

Tanaka N, Aronova A, Schwer B. 2007. Ntr1 activates the Prp43 helicase to trigger release of lariat-intron from the spliceosome. Genes Dev 21: $2312-2325$.

Tazi J, Kornstädt U, Rossi F, Jeanteur P, Cathala G, Brunel C, Lührmann R. 1993. Thiophosphorylation of U1-70K protein inhibits pre-mRNA splicing. Nature 363: 283-286.

Toor N, Keating KS, Taylor SD, Pyle AM. 2008. Crystal structure of a selfspliced group II intron. Science 320: 77-82.

Tsai RT, Fu RH, Yeh FL, Tseng CK, Lin YC, Huang YH, Cheng SC. 2005. Spliceosome disassembly catalyzed by Prp43 and its associated components Ntr1 and Ntr2. Genes Dev 19: 2991-3003.

Tsai RT, Tseng CK, Lee PJ, Chen HC, Fu RH, Chang KJ, Yeh FL, Cheng SC. 2007. Dynamic interactions of Ntr1-Ntr2 with Prp43 and with U5 govern the recruitment of Prp43 to mediate spliceosome disassembly. Mol Cell Biol 27: 8027-8037. 
Tseng CK, Cheng SC. 2008. Both catalytic steps of nuclear pre-mRNA splicing are reversible. Science 320: 1782-1784.

Turner IA, Norman CM, Churcher MJ, Newman AJ. 2004. Roles of the U5 snRNP in spliceosome dynamics and catalysis. Biochem Soc Trans 32: $928-931$.

Umen JG, Guthrie C. 1995. The second catalytic step of pre-mRNA splicing. RNA 1: 869-885.

Valadkhan S. 2005. snRNAs as the catalysts of pre-mRNA splicing. Curr Opin Chem Biol 9: 603-608.

Valadkhan S, Manley JL. 2001. Splicing-related catalysis by protein-free snRNAs. Nature 413: 701-707.

Valadkhan S, Mohammadi A, Jaladat Y, Geisler S. 2009. Protein-free small nuclear RNAs catalyze a two-step splicing reaction. Proc Natl Acad Sci 106: $11901-11906$.

Valadkhan S, Mohammadi A, Wachtel C, Manley JL. 2007. Protein-free spliceosomal snRNAs catalyze a reaction that resembles the first step of splicing. RNA 13: 2300-2311.

Valcárcel J, Gaur RK, Singh R, Green MR. 1996. Interaction of U2AF65 RS region with pre-mRNA branch point and promotion of base pairing with U2 snRNA. Science 273: 1706-1709.

Vidovic I, Nottrott S, Hartmuth K, Lührmann R, Ficner R. 2000. Crystal structure of the spliceosomal $15.5 \mathrm{kD}$ protein bound to a U4 snRNA fragment. Mol Cell 6: 1331-1342.

Wachtel C, Manley JL. 2009. Splicing of mRNA precursors: The role of RNAs and proteins in catalysis. Mol Biosyst 5: 311-316.

Wahl MC, Will CL, Lührmann R. 2009. The spliceosome: Design principles of a dynamic RNP machine. Cell 136: 701-718.

Wang Z, Burge CB. 2008. Splicing regulation: From a parts list of regulatory elements to an integrated splicing code. RNA 14: 802-813.

Wang C, Chua K, Seghezzi W, Lees E, Gozani O, Reed R. 1998. Phosphorylation of spliceosomal protein SAP 155 coupled with splicing catalysis. Genes Dev 12: 1409-1414.

Ward AJ, Cooper TA. 2010. The pathobiology of splicing. J Pathol 220: $152-163$.
Warkocki Z, Odenwälder P, Schmitzová J, Platzmann F, Stark H, Urlaub H, Ficner R, Fabrizio P, Lührmann R. 2009. Reconstitution of both steps of Saccharomyces cerevisiae splicing with purified spliceosomal components. Nat Struct Mol Biol 16: 1237-1243.

Webby CJ, Wolf A, Gromak N, Dreger M, Kramer H, Kessler B, Nielsen ML, Schmitz C, Butler DS, Yates JR, et al. 2009. Jmjd6 catalyses lysyl-hydroxylation of U2AF65, a protein associated with RNA splicing. Science 325: 90-93.

Will CL, Lührmann R. 2006. Spliceosome structure and function. In The RNA world, 3rd ed. (ed. R.F. Gesteland et al.), pp. 369-400. Cold Spring Harbor Laboratory Press, Cold Spring Harbor, NY.

Wolf E, Kastner B, Deckert J, Merz C, Stark H, Lührmann R. 2009. Exon, intron and splice site locations in the spliceosomal B complex. EMBO J 28: 2283-2292.

Xiao SH, Manley JL. 1997. Phosphorylation of the ASF/SF2 RS domain affects both protein-protein and protein-RNA interactions and is necessary for splicing. Genes Dev 11: 334-344.

Xiao X, Wang Z, Jang M, Burge CB. 2007. Coevolutionary networks of splicing cis-regulatory elements. Proc Natl Acad Sci 104: $18583-18588$.

Xu YZ, Query CC. 2007. Competition between the ATPase Prp5 and branch region-U2 snRNA pairing modulates the fidelity of spliceosome assembly. Mol Cell 28: 838-849.

Yang K, Zhang L, Xu T, Heroux A, Zhao R. 2008. Crystal structure of the $\beta$-finger domain of Prp8 reveals analogy to ribosomal proteins. Proc Natl Acad Sci 105: 13817-13822.

Zhang L, Shen J, Guarnieri MT, Heroux A, Yang K, Zhao R. 2007. Crystal structure of the C-terminal domain of splicing factor Prp8 carrying retinitis pigmentosa mutants. Protein Sci 16: 1024-1031.

Zhang L, Xu T, Maeder C, Bud LO, Shanks J, Nix J, Guthrie C, Pleiss JA, Zhao R. 2009. Structural evidence for consecutive Hel308-like modules in the spliceosomal ATPase Brr2. Nat Struct Mol Biol 16: $731-739$. 


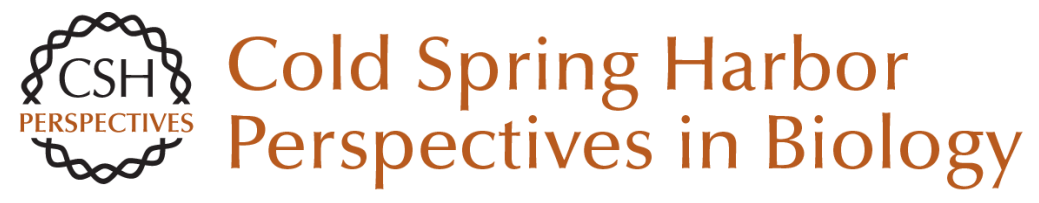

\section{Spliceosome Structure and Function}

Cindy L. Will and Reinhard Lührmann

Cold Spring Harb Perspect Biol 2011; doi: 10.1101/cshperspect.a003707 originally published online December 30, 2010

\section{Subject Collection RNA Worlds}

Alternate RNA Structures

Marie Teng-Pei Wu and Victoria D'Souza

Approaches for Understanding the Mechanisms

of Long Noncoding RNA Regulation of Gene

Expression

Patrick McDonel and Mitchell Guttman

Principles and Practices of Hybridization Capture

Experiments to Study Long Noncoding RNAs That

Act on Chromatin

Matthew D. Simon and Martin Machyna

Linking RNA Sequence, Structure, and Function

on Massively Parallel High-Throughput

Sequencers

Sarah K. Denny and William J. Greenleaf

Extensions, Extra Factors, and Extreme

Complexity: Ribosomal Structures Provide

Insights into Eukaryotic Translation

Melanie Weisser and Nenad Ban

Nascent RNA and the Coordination of Splicing with Transcription

Karla M. Neugebauer

Combining Mass Spectrometry (MS) and Nuclear

Magnetic Resonance (NMR) Spectroscopy for Integrative Structural Biology of Protein-RNA

Complexes

Alexander Leitner, Georg Dorn and Frédéric H.-T. Allain
Structural Biology of Telomerase

Yaqiang Wang, Lukas Susac and Juli Feigon

Structural Insights into Nuclear pre-mRNA

Splicing in Higher Eukaryotes

Berthold Kastner, Cindy L. Will, Holger Stark, et al.

What Are 3' UTRs Doing?

Christine Mayr

Single-Molecule Analysis of Reverse

Transcriptase Enzymes

Linnea I. Jansson and Michael D. Stone

\section{CRISPR Tools for Systematic Studies of RNA}

Regulation

Jesse Engreitz, Omar Abudayyeh, Jonathan Gootenberg, et al.

Relating Structure and Dynamics in RNA Biology Kevin P. Larsen, Junhong Choi, Arjun Prabhakar, et al.

Beyond DNA and RNA: The Expanding Toolbox of

Synthetic Genetics Alexander I. Taylor, Gillian Houlihan and Philipp Holliger

For additional articles in this collection, see http://cshperspectives.cshlp.org/cgi/collection/

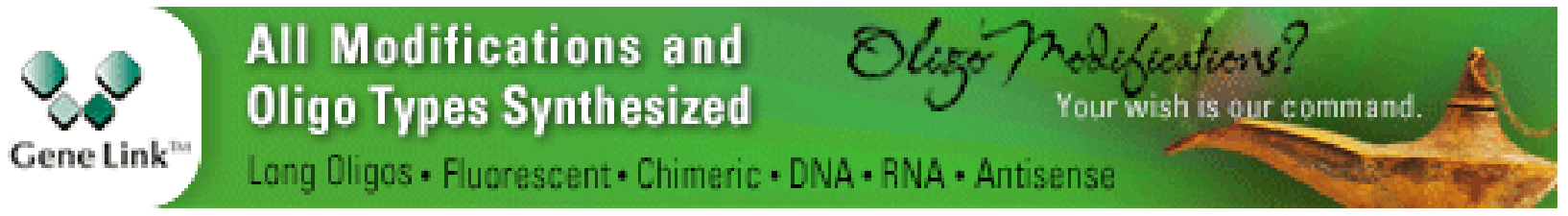

Copyright (C 2011 Cold Spring Harbor Laboratory Press; all rights reserved 
Discovering and Mapping the Modified Nucleotides That Comprise the Epitranscriptome of mRNA

Bastian Linder and Samie R. Jaffrey
Structural Basis of Nuclear pre-mRNA Splicing:

\section{Lessons from Yeast}

Clemens Plaschka, Andrew J. Newman and Kiyoshi Nagai

For additional articles in this collection, see http://cshperspectives.cshlp.org/cgi/collection/

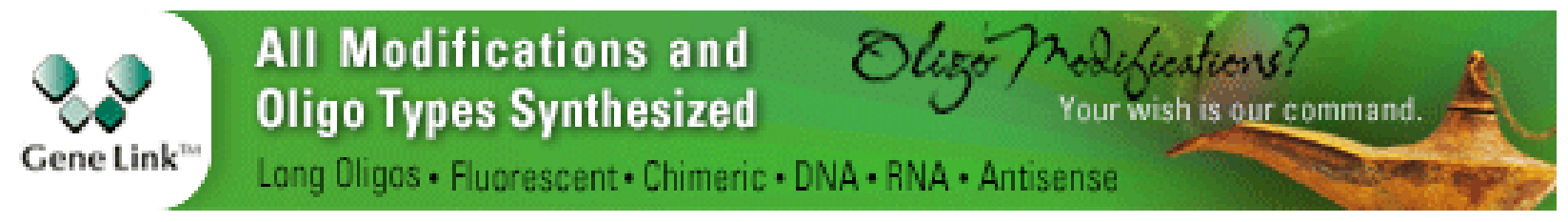

Copyright (C) 2011 Cold Spring Harbor Laboratory Press; all rights reserved 